\title{
LA SUPERACIÓN DEL PARADIGMA TERRITORIAL Y SUS EFECTOS EN EL DERECHO ADMINISTRATIVO
}

BASES NORMATIVAS DEL DERECHO ADMINISTRATIVO TRANSNACIONAL

JORGE AGUDO GONZÁLEZ 
SUMARIO

I. INTRODUCCIÓN. II. EL PRINCIPIO DE TERRITORIALIDAD EN LA TEORÍA GENERAL DEL ESTADO Y EN LA TEORÍA GENERAL DEL DERECHO. 1. EL PRINCIPIO DE TERRITORIALIDAD Y EXCLUSIVIDAD DEL PODER SOBERANO. 2. EL DERECHO ESTATAL «HACIA EL EXTERIOR». 2.1. FUNDAMENTOS DEL DERECHO INTERNACIONAL. 2.2. CONFLICTOS DE LEYES Y DERECHO INTERNACIONAL PRIVADO. III. LA PÉRDIDA DE CENTRALIDAD DEL PRINCIPIO DE TERRITORIALIDAD. 1. SUPERACIÓN DE LA EXCLUSIVIDAD DEL DERECHO ESTATAL. 1.1. FRAGMENTACIÓN JURÍDICA Y «NORMAS» (PRIVADAS) INTERNACIONALES. 1.2. EL DERECHO ADMINISTRATIVO ES DERECHO INTERNACIONAL Y VICEVERSA. 1.3. RELACIONES ENTRE ORDENAMIENTOS ESTATALES. 2. SUPERACIÓN DE LA DIVISIÓN DERECHO PÚBLICO VERSUS DERECHO PRIVADO. IV. CONSIDERACIONES FINALES: EL «CARÁCTER RELACIONAL» DEL DERECHO ADMINISTRATIVO TRANSNACIONAL. 1. DE LA EXCLUSIVIDAD Y LA COMPLITUD DEL DERECHO ADMINISTRATIVO ESTATAL A LAS RELACIONES INTERORDINAMENTALES Y LA CONFLICTUALIDAD. 2. DE LA CONCEPCIÓN AUTORITARIA Y CENTRADA EN SITUACIONES JURÍDICAS ESTÁTICAS, A UNA CONCEPCIÓN EX PARTE CIVIUM Y FOCALIZADA EN RELACIONES JURÍDICAS DINÁMICAS. 


\title{
LA SUPERACIÓN DEL PARADIGMA TERRITORIAL Y SUS EFECTOS EN EL DERECHO ADMINISTRATIVO Bases normativas del Derecho Administrativo transnacional
}

\author{
JORGE AGUDO GONZÁLEZ ${ }^{1}$ \\ Profesor Titular de Derecho Administrativo \\ Acreditado como Catedrático \\ Universidad Autónoma de Madrid
}

\section{INTRODUCCIÓN}

El Derecho Administrativo aborda con cada vez mayor asiduidad la regulación de fenómenos jurídicos que de forma sintética podemos calificar como transnacionales. El sentido jurídico que evoca esta noción, está ligada a la insuficiencia del Derecho Administrativo estatal para ordenar plenamente las relaciones jurídicas así caracterizadas.

La realidad jurídica a la que nos referimos es bastante diversa. Se pueden distinguir dos aproximaciones a los fenómenos de la transnacionalidad: una estricta y otra más heterogénea. La vertiente estricta se puede identificar en fenómenos transnacionales comunes en organizaciones de integración económica como la Unión Europea. Nos referimos a relaciones jurídicas surgidas en el ejercicio de las libertades comunitarias, articuladas fundamentalmente mediante las distintas variantes del principio de reconocimiento mutuo ${ }^{2}$. Los ejemplos van desde la prestación de servicios profe-

\footnotetext{
${ }^{1}$ Facultad de Derecho de la Universidad Autónoma de Madrid, Campus de Cantoblanco, Crtra. de Colmenar Viejo Km. 16, C/ Kelsen N. ${ }^{1}$, 28049 Madrid. E-mail: jorge.agudo@uam.es. Este artículo se enmarca en el proyecto «Relaciones jurídicas transnacionales en el mercado interior y justicia administrativa» (DER2017-84500-P) del Ministerio de Ciencia, Innovación y Universidades.

${ }^{2}$ Como es sabido, la STJCE de 20 de febrero de 1979 (as. Cassis de Dijon) consolidó la aplicación del reconocimiento mutuo en el ámbito de la libre circulación de mercancías en ámbitos no armonizados. El reconocimiento mutuo supone que todos los productos provenientes de un Estado miembro (Estado de origen) puedan ser comercializados libremente en el territorio de cualquier otro Estado miembro (Estado de destino), siempre que hayan sido fabricados conforme a la regulación del primero que se estima equivalente a la vigente en el segundo Estado. La ampliación aplicativa del reconocimiento mutuo se ha consolidado, posteriormente,
} 
sionales o el establecimiento de actividades económicas de ciudadanos y empresas europeas en Estados miembros distintos al propio, a la comercialización de bienes producidos en un determinado Estado en cualquier otro europeo. Esta expresión de la transnacionalidad es propia de la Unión Europea, pero también se ha ido generalizando en otras organizaciones de integración económica ${ }^{3}$.

Desde una perspectiva más amplia, también se han calificado como transnacionales a otros fenómenos jurídicos sometidos a normas de distinta procedencia y que, en muchos casos, están ligados a la actividad de grandes multinacionales o grupos empresariales en un contexto global. Aquí las relaciones jurídicas quedan gobernadas no ya sólo por normas nacionales, europeas o internacionales convencionales, sino también por otras «normas» privadas internacionales que en muchos casos se aplican incluso en detrimento de las anteriores; aquí estamos pensando tanto en normas dictadas por entidades privadas de normalización, como también en otras elaboradas por entidades o asociaciones internacionales de empresas privadas en sectores de actividad determinados ${ }^{4}$. Se trata, como se puede observar, de fenómenos heterogéneos, pero que comparten ciertas manifestaciones típicas en el plano jurídico como la hibridación (nacional/internacional, público/privado) y la conflictualidad entre normas aplicables de muy distinto origen.

En este estudio abordaremos estos fenómenos jurídicos desde la perspectiva del principio de territorialidad, para proyectarla específicamente sobre el Derecho Administrativo. Piénsese que la transnacionalidad, entendida en los dos sentidos indicados, es un fenómeno inherente a la globalización; podría decirse, por tanto, que es una manifestación opuesta a la tradicional territorialidad y exclusividad del Derecho Administrativo como Derecho estatutario del Estado.

La intención es, en síntesis, confrontar la construcción clásica del Derecho Administrativo sobre el pilar estructurante de la territorialidad, con los procesos de inexorable desterritorialización del Derecho Administrativo. Esa comparación nos mostrará una superación de aquel principio, ya que esos fenómenos no pueden ser íntegramente explicados con base en los parámetros clásicos. Sin embargo, no parece razonable hablar de

con su extensión a otras libertades básicas y en ámbitos armonizados y no armonizados. Para ser exactos habría que decir que la primera referencia al reconocimiento mutuo vinculada a las libertades básicas del mercado interior se produjo en relación con el reconocimiento de títulos y diplomas (art. 57.1 del Tratado de Roma de 1957, vigente art. 54.1 del TFUE).

3 El reconocimiento mutuo también se ha generalizado en la OMC. En el marco del General Agreement on Tariffs and Trade (GATT), el Acuerdo sobre Obstáculos Técnicos al Comercio (OTC) regula el reconocimiento de la evaluación de la conformidad de los productos fabricados en otro Estado. En síntesis, este instrumento garantiza el derecho de comercialización de un producto en el país de destino, en virtud del reconocimiento de la actuación administrativa que verifica la conformidad de la fabricación con la normativa del país de origen y fundamentada en la equivalencia de las reglamentaciones de ambos Estados. El propio acuerdo insta a los Estados parte a la negociación de Mutual Recognition Agreements (MRAs). En una línea similar, el General Agreement on Trade in Services (GATS). También ha sido incorporado al art. 908 del Capítulo 9. ${ }^{\circ}$ del NAFTA.

4 El catálogo es desde luego más amplio. Un intento de catalogación en H. C. H. HOFMANN (2013): «Transnational and Trans-Territorial Rule-Making. A Basic Framework», Missouri Law Rw 78. 
una inhabilitación del mismo. Frente a las tesis maximalistas, de tono más bien idealista, que pretenden ubicarnos en un escenario post-estatal cuyo ámbito natural sería la supraterritorialidad ${ }^{5}$, aquí mantenemos que todavía es innegable que el Estado y el principio de territorialidad siguen asumiendo un papel relevante. Admitido este presupuesto, otra premisa resulta también innegable: el Estado ya no juega un papel «monopolístico» ni en el ámbito estrictamente interno, ni en el contexto internacional.

La globalización se caracteriza por la generalización de fenómenos socio-económicos que rebasan los límites estatales y que sobrepasan las capacidades nacionales para afrontar con solvencia su regulación y gestión, debido tanto a la relevancia supraestatal de los problemas, como a los múltiples intereses en juego o a la variedad de agentes involucrados. Centrados en los fenómenos económicos, concurren diferentes procesos que acreditan el debilitamiento de la posición del Estado. Pueden simplificarse en dos: $\left.1 .^{\circ}\right)$ El ordoliberalismo y los procesos de privatización, liberalización y de control de déficit, que alzan al mercado como proveedor de las necesidades sociales como alternativa al Estado ${ }^{6}$ y $\left.2 .^{\circ}\right)$ La globalización de la economía y la desterritorialización de los mercados, que evidencian la superación de la conexión Estado-nación-economía ${ }^{7}$, y también de la relación Derecho Administrativo Económico-economía nacional ${ }^{8}$.

El contexto actual nos sitúa, por tanto, en un marco donde confluyen asimétrica y paradójicamente procesos de globalización con una (todavía) predominante naturaleza estatal de las normas jurídicas. La imposibilidad de regular todas las dimensiones y efectos de esos procesos globales desde una posición estatista, per-

5 Estas propuestas, aparte de poco realistas y bastante indefinidas, resultan ser, en última instancia, contradictorias. Por una parte, porque difícilmente puede hablarse en el contexto actual de liquidación del Estado. De hecho, hay quienes propugnan procesos de fortalecimiento del Estado como F. LAPORTA SAN MIGUEL (2005): «Globalización e imperio de la Ley. Algunas dudas westfalianas», Anuario de la Facultad de Derecho de la UAM 19, 182. Por otra, porque este tipo de planteamientos, que se detectan tras las ideas de un Estado Federal Europeo o, dentro del más puro idealismo, de la noción de Estado mundial, corren el riesgo de caer en un discurso vacío y simplista, cuando no incurren en las mismas limitaciones que imputan al principio de territorialidad en su versión clásica, pues muestran una disposición a reproducir la noción de jurisdicción territorial estatal, pero a un nivel territorial superior. Una visión crítica en P. MERCADO PACHECO (2005): «Estado y globalización. ¿Crisis o redefinición del espacio político estatal?», Anuario de la Facultad de Derecho de la UAM 9, 142, y en K-H. LADEUR (2010): «The State in International Law», Comparative Research in Law E Political Economy. Research Paper 27,10 y 11 .

6 S. BATTINI (2006): «The Globalization of Public Law», European Rw of Public Law 18(1), 5, remarca el protagonismo del libre mercado en la evolución que imprime la globalización en el Derecho Público.

7 J. HABERMAS (2001): «El valle de lágrimas de la globalización», Claves de la Razón Práctica 109, 6, afirma que «está siendo relegada a un segundo plano la "autosuficiencia funcional" de la economía interna». También, P. MERCADO PACHECO (2005: 129-134), o S. BATTINI (2006: 5 y ss.).

8 Así se constata en el Derecho Mercantil. R. ILLESCAS ORTIZ (2005): «Derecho Mercantil y Globalización», Anuario de la Facultad de Derecho de la UAM 9, 80, afirma que el Derecho Mercantil va adquiriendo un conjunto normativo con vocación de universalidad donde el territorio es global. 
mite deducir que la juridicidad de las relaciones surgidas en ese contexto global se basa en nuevas formas de ordenación que dependen de las conexiones que los ordenamientos nacionales entablan con otros ordenamientos (internacionales y nacionales). Sólo de este modo cabe culminar el régimen jurídico de esas relaciones jurídicas. Esta visión relacional quiebra la originaria exclusividad del Derecho estatal, pero también condiciona la idea de plenitud del ordenamiento interno, a la vez que genera una percepción dinámica y singularizable del régimen jurídico de cada relación jurídico-administrativa.

Esta realidad jurídica confirma la progresiva desvinculación del Derecho Administrativo de su vocación original de estatalidad con proyección «ad intra». Fenómenos conocidos como los de la conformación de un Derecho Administrativo Global o de un Derecho Administrativo Internacional, nos han mostrado ya una proyección supraterritorial del Derecho Administrativo, que no encaja con su concepción estatutaria clásica como Derecho del Estado. Esa proyección se ratifica con la incorporación de la vertiente transnacional del Derecho Administrativo, que no es más que una expresión particular de esos procesos más amplios.

Para afrontar el análisis propuesto, comenzaremos nuestro estudio con una exposición sobre la trascendencia del principio de territorialidad en la Teoría General del Estado y en la Teoría jurídica, en lo que se podría calificar como una síntesis del planteamiento clásico. Esta primera parte abordará la trascendencia del territorio desde el plano teórico, con especial interés en su configuración como base y límite del poder público y, en consecuencia, de la validez y eficacia de los actos jurídicos-públicos, pero también de los derechos reconocidos por el Estado. La primera parte también pretende poner de relieve la trascendencia del territorio en las relaciones entre órdenes normativos, fundamentalmente, en la relación entre Derecho estatal y Derecho Internacional.

Realizado ese estado de la cuestión, el estudio abordará la más reciente incidencia de los fenómenos que se materializan en el vigente contexto de fragmentación y pluralismo jurídico. Esos apartados pretenderán mostrar una realidad global que supera la configuración clásica del principio de territorialidad y, por ello, que invalida su capacidad explicativa de fenómenos jurídicos como los de tipo transnacional.

La convivencia de parámetros clásicos y de fenómenos novedosos nos situará frente a la necesidad de explicar un panorama jurídico-administrativo transformador. En coherencia con el objeto de nuestro estudio, mostraremos cómo la desterritorialización del Derecho tiene implicaciones directas no sólo en las relaciones entre órdenes normativos, sino también en la summa divisio público-privado, así como en la vis autoritaria que tradicionalmente ha caracterizado al Derecho Administrativo. El resultado evidencia una transformación jurídica que supera el carácter exclusivo, pleno y estático del Derecho Administrativo estatal, abriendo paso a un Derecho Administrativo compartido, basado en relaciones interordinamentales y de carácter dinámico. 


\section{EL PRINCIPIO DE TERRITORIALIDAD EN LA TEORÍA GENERAL DEL ESTADO Y EN LA TEORÍA GENERAL DEL DERECHO}

\section{El principio de territorialidad y exclusividad del poder soberano}

La trascendencia del principio de territorialidad, o para ser más exactos, del territorio, en la configuración moderna del Estado, es un lugar común en la Teoría General del Estado9. La Teoría General del Estado aborda el concepto de territorio como uno de los tres elementos constitutivos del concepto de Estado (territorio, población y soberanía). Haciendo abstracción de los matices, todas las teorías asumen al territorio como un elemento configurador inherente a la propia noción de Estado: no hay Estado sin territorio ${ }^{10}$. De esa consustancialidad se derivan varias consecuencias que son indisociables $y$, por tanto, se encuentran intervinculadas.

La primera de esas consecuencias es la concepción de la soberanía como estrictamente nacional, esto es, no dependiente de poder externo alguno y, por ello, rigurosamente unilateral, unitaria y exclusiva en el territorio estatal ${ }^{11}$. El principio de exclusividad, inherente a la territorialidad del poder soberano, impide que cualquier otro poder no sometido al Estado ejerza funciones de autoridad en ese territorio. Las expresiones del principio pueden desagregarse en una vertiente interna y otra externa.

Desde una perspectiva «ad intra», el territorio se convierte en la expresión espacial del poder soberano del Estado; dicho de otro modo, el principio de territorialidad establece el ámbito en el que se conforma y consolida el poder soberano. El territorio

9 La relevancia del territorio como elemento configurador de espacios sometidos al Derecho propio de la tierra ahonda sus raíces en el proceso de securalización del poder del Rey soberano. Véase, M. LOUGHLIN, (2010): Foundations of Public Law, Oxford: OUP, 37 y ss. Una reconstrucción de las transformaciones de la territorialidad desde la época medieval en $B$. TESCHKE (2011): "The metamorphoses of European territoriality: a historical reconstruction», M. BURGESS y H. VOLLAARD (eds.), State Territoriality and European Integration, Nueva York: Routledge, 62, concibiendo ese proceso como «a sequence from feudal personalised and de-centralised, via absolutist personalised and centralised, to modern de-personalised and centralised político-spatial organisation».

10 K. STERN (1987): Derecho del Estado de la República Federal de Alemania, Madrid: CEC, 443-444, afirma que «el Estado moderno se convierte en un Estado territorial (territorium clausum)», donde «el principio de territorialidad entra en el lugar del principio de personalidad».

${ }^{11}$ En este sentido, O. MAYER (1906): Le Droit Administratif Allemand, París: V. Giard \& E. Brière, 354; G. JELLINEK (1981): Teoría General del Estado, Buenos Aires: Ed. Albatros, 295 y ss.; R. CARRÉ DE MALBERG (1998): Teoría General del Estado, México D. F.: Fondo de Cultura Económica, 23; L. DUGUIT (2005): Manual de Derecho Constitucional, Granada: Comares, 63. Más modernamente, H. NAWIASKY (2002): Teoría General del Derecho, Granada, Comares, 96; N. BOBBIO (2006): Estado, Gobierno y Sociedad. Por una teoría general de la política, México D. F.: Fondo de Cultura Económica, 108; o P. GROSSI (1996): «Un Diritto senza Stato (La nozione di autonomia come fondamento della constituzione giuridica medievale)», Quaderni Fiorentini 25, 272 y 273.

N. ${ }^{\circ} 103$, septiembre-diciembre 2018, págs 155-190 
se concibe, por tanto, como elemento definidor y constitutivo del Estado ${ }^{12}$, donde reside el titular de la soberanía que, en las teorías más refinadas del iuspositivismo, culminaría con la atribución de personalidad jurídica al Estado ${ }^{13}$.

Con la residencia de la soberanía en un titular colectivo (soberanía nacional), la teorización sobre el concepto de Estado consigue dos logros fundamentales: $1 .^{\circ}$ ) Ubicar al titular de la soberanía en una sede en la que es «físicamente» imposible su ejercicio; el poder ilimitado que se concentra en el Estado soberano necesariamente tiene que predicarse de realidades jurídicas que se materializan en un orden jurídico; $\left.2 .^{\circ}\right)$ No atribuir el poder soberano a ninguno de los poderes u órganos del Estado; estos «sólo» ejercen funciones jurídicas, estos es, la realización in concretum del poder soberano.

Si el Estado se constituye como un conjunto de poderes sometidos a Derecho, sus prerrogativas pueden estar sujetas a límites ${ }^{14}$. De hecho, el Estado puede autolimitar su poder y reconocer derechos a los ciudadanos, caracterizándoles como sujetos de dere$\operatorname{chos}^{15}$. «La subjetividad jurídica se afirma en oposición al Estado. Esta subjetividad se exterioriza mediante el reconocimiento que hace el Estado al individuo de su carácter de miembro en la comunidad popular; pero esto implica el reconocimiento del hombre como persona, esto es, como individuo que posee una esfera de Derecho Público». Así se expresaba G. JELLINEK ${ }^{16}$ para iniciar el desarrollo de su teoría sobre el status jurídico de la personalidad que concreta la relación jurídica del Estado con el individuo.

Las consideraciones precedentes tienen consecuencias en la teoría jurídica. Al constituirse el territorio en un elemento no autónomo del poder soberano, no sólo es base para su propia existencia y conformación, sino que también predetermina los límites al poder del Estado. Para la teoría jurídica el principio de territorialidad tiene relevancia en dos aspectos: el de la validez del ordenamiento jurídico interno y el de la aplicación efectiva del Derecho. Ambas consideraciones identifican al principio de territorialidad como principio determinante de la autoridad normativa y ejecutiva del Estado.

En cuanto al primer aspecto, la validez de las normas, en el territorio del Estado el Derecho es exclusivamente Derecho estatal. De ello se deriva que el Derecho estatal es la única fuente de creación de normas válidas. El Derecho estatal funda su validez en su creación regular de conformidad con la norma superior que ordena todo el sistema de fuentes: la norma fundante básica «kelseniana» ${ }^{17}$. Ahora bien, desde un

12 El territorio es el presupuesto necesario del ejercicio del poder del Estado y, por ello, sirve de fundamento real del ejercicio total del poder de imperium (G. JELLINEK: 1981, 295 y ss.).

13 El autor con la aproximación teórica más acabada sobre el Estado como sujeto de Derecho quizás sea G. JELLINEK (1981), aunque tampoco se puede dejar de destacar la obra de R. CARRÉ DE MALBERG (1998: 29 y ss.).

${ }^{14}$ G. JELLINEK (1981: 290 y 358).

15 Véase, J. CHEVALLIER (2015): El Estado de Derecho, Bogotá: Universidad Externado, 26 y ss.

16 G. JELLINEK (1981: 306).

17 Para H. KELSEN (2007): Compendio de Teoría General del Estado, México D. F.: Colofón, 140, al concebir al Estado como un orden jurídico, los elementos del Estado se transforman en criterios de validez: el territorio constituye un «límite de validez espacial». 
plano negativo, el principio de territorialidad también establece límites, en la medida en que el territorio se concibe como límite espacial de la norma vigente ${ }^{18}$.

Respecto a la aplicación efectiva del Derecho válido, bajando, por tanto, al plano de la eficacia práctica del orden jurídico, la clave se encuentra en la posibilidad de ejercer el poder de coerción inherente al poder soberano. En este ámbito, el Derecho Administrativo se erige como un instrumento clave para la consolidación del poder interno y, por ello, como un orden normativo concebido desde el poder de imperium, la autoridad y la prerrogativa (aunque no exclusivamente) ${ }^{19}$. En otras palabras, la vis autoritaria del Derecho Administrativo le conforma como el estatuto de las normas de conducta del Estado ${ }^{20}$ que se impone, incluso coercitivamente, sobre las personas (nacionales o no) sitas en el territorio nacional ${ }^{21}$.

Para la teoría jurídica esta percepción tiene su particular constatación en la división sistemática entre Derecho Público y Derecho Privado. Se concretan dos lógicas jurídicas distintas: la del Derecho Público, entendido como un orden jurídico de intervención y control de las relaciones jurídico-públicas en general y de la economía interna en particular; y la del Derecho Privado, como Derecho de la personalidad, la propiedad y el contrato y, por ello, del mercado, basado en la reciprocidad y el pacta sunt servanda. Una doble lógica que se materializa en la primacía de lo público (del Derecho del Estado, del poder de coerción) sobre lo privado ${ }^{22}$ y, en consecuencia, en la subordinación de los intereses privados a los generales y de la Economía al Dere$\mathrm{cho}^{23}$. Esto también permite entender la diferente intensidad del principio de terri-

18 Una norma jurídica estatal podría pretender regular lo que sucede fuera de su territorio, aunque no existiría garantía alguna de que la norma fuera aplicada. Para H. NAWIASKY (2002: 96), ese resultado justifica la autolimitación de los Estados para evitar ver incumplido su Derecho. En el marco de las relaciones internacionales no ha sido extraña la extensión de los efectos de un ordenamiento a otro Estado. Véase, S. NICOLIN (2005): Il mutuo riconoscimento tra mercato interno e sussidiarietà, Milán: CEDAM, 203; A. S. GERONTAS (2013): «Deterritorialization in Administrative Law: Exploring Transnational Administrative Decisions», Columbia Journal of European Law Vol. 19(3), 12. Como señalan A. REMIRO BROTONS et al. (2010): Derecho Internacional. Parte General, Valencia: Tirant lo Blanch, 91 y ss., los Estados pueden legislar o juzgar sobre personas situadas y acontecimientos producidos fuera de su territorio, siempre y cuando los Estados cuenten con un título o fundamento para ello.

19 El Estado goza del privilegio de fijarse a sí mismo las reglas que enmarcan el ejercicio de sus poderes, quedando sujeto a un Derecho especial (el Derecho Administrativo) (J. CHEVALLIER: 2015, 29).

${ }^{20}$ El Derecho Administrativo como «el Derecho Público interno del Estado por excelencia» (E. GARCÍA DE ENTERRÍA y T. R. FERNÁNDEZ RODRÍGUEZ (1997): Curso de Derecho Administrativo I, 8. ${ }^{\text {a }}$ ed., Madrid: Civitas, 37).

21 La puissance publique y el poder de dominación de M. HAURIOU (2003): Principios de Derecho Público y Constitucional, Granada: Comares, 196 y ss.

${ }^{22}$ La distinción Derecho Público/Derecho Privado responde a la «teoría del plusvalor», que atribuye al Estado un valor jurídico superior que al resto de sujetos jurídicos. En este sentido, G. NAPOLITANO (2014): La lógica del diritto amministrativo, Bolonia: Il Mulino, 48.

${ }^{23}$ M. HAURIOU (2003: 180-185), N. BOBBIO (2006: 30) o F. CARNELUTTI (2010): Cómo nace el Derecho, Bogotá: Ed. Temis, 15.

N. ${ }^{\circ}$ 103, septiembre-diciembre 2018, págs 155-190 
torialidad del Derecho estatal en la esfera privada, donde sí se habilita la aplicación del Derecho extranjero en las relaciones jurídico-privadas con proyección internacional (Derecho Internacional Privado) ${ }^{24}$.

\section{El Derecho estatal «hacia el exterior»}

\subsection{Fundamentos del Derecho Internacional}

El principio de exclusividad derivado de la territorialidad estatal condiciona los términos en que se entablan las relaciones del Estado en su proyección hacia el exterior. Si el poder soberano del Estado es exclusivo, no es susceptible de oposición dentro de su territorio, pero tampoco puede ser sometido a otros Estados en sus relaciones exteriores. La soberanía garantiza la independencia del Estado respecto de terceros $^{25}$, condicionando sus relaciones al reconocimiento recíproco en términos de igualdad $^{26}$.

Desde la perspectiva que aquí nos interesa, las relaciones internacionales plantean problemas en el marco de las relaciones entre normas. Parece evidente que la exclusividad del Derecho estatal encuentra condicionantes en sus relaciones con el Derecho Internacional. Aquí adquiere plena relevancia la discusión sobre la fundamentación y consecuente validez del Derecho Internacional. No es momento de abordar en profundidad las distintas tesis relativas al fundamento del Derecho Internacional ${ }^{27}$, pero merece la pena realizar una contextualización desde la posición del Estado.

Sintéticamente, esas tesis pueden dividirse en tesis voluntaristas y antivoluntaristas. Las primeras fundamentan de modo exclusivo el Derecho Internacional en la voluntad de los Estados, mientras que las segundas otorgan validez al Derecho Internacional con base en una fundamentación propia y ajena al Estado. La discusión sobre el fundamento de la juridicidad del Derecho Internacional conecta con otra cuestión relevante: la relativa al primado del orden jurídico estatal frente al orden jurídico internacional, lo que nos inserta en la dicotomía dualismo versus monismo. Las tesis voluntaristas coinciden con las dualistas al explicar las relaciones con el Derecho

${ }^{24}$ La relación entre principio de territorialidad y su diferente trascendencia en la división Derecho Público/Derecho Privado, en O. DUBOS (2010): «Le territoire», J-B. AUBY, L'influence du Droit Européen sur les catégories du Droit Public, París: Dalloz, 356.

25 R. CARRÉ DE MALBERG (1998: 81-82) afirma que la soberanía se descompone en soberanía interna y externa. La primera implica superioridad y negación de toda subordinación, y la segunda representa la independencia frente a otros Estados. En esa misma dirección, G. NAPOLITANO (2014: 4).

26 La soberanía del Estado implica relaciones basadas en el reconocimiento recíproco, en la equiparación de los Estados y la aplicación de criterios de justicia conmutativa (R. CARRÉ DE MALBERG: 1998, 81).

27 Sobre esta cuestión, véase M. DÍEZ DE VELASCO (1978): Instituciones de Derecho Internacional Público, Madrid: Tecnos, 60 y ss., y J. A. PASTOR RIDRUEJO (2008): Curso de Derecho Internacional Público y Organizaciones Internacionales, 12. ${ }^{\mathrm{a}}$ ed., Madrid: Tecnos, 34 y ss. 
Internacional mediante el primado del Derecho estatal, mientras que las tesis antivoluntaristas parten de planteamientos monistas y, por ello, asumen la subordinación del ordenamiento interno al internacional.

Conjugando ambos pares conceptuales (voluntarismo/dualismo y antivoluntarismo/monismo), puede sintetizarse afirmando que, en el primer caso, es el propio Derecho estatal el que confiere validez al Derecho Internacional y que, en consecuencia, éste se subordina al Derecho interno ${ }^{28}$ : el otorgamiento de carta de naturaleza al Derecho Internacional requiere un acto normativo de transformación en Derecho estatal que le confiera validez interna ${ }^{29}$. El segundo par conceptual (antivoluntarismo/ monismo) nos sitúa en un escenario distinto, pues la fuente del Derecho Internacional es independiente de los ordenamientos nacionales y le otorga una prevalencia que le permite imponerse sobre los Derechos estatales ${ }^{30}$.

En la evolución de las Constituciones nacionales, sobre todo tras la Segunda Guerra Mundial, se observa una tendencia a la superación del dualismo voluntarista. Se puede hablar de una clara orientación hacia el monismo y el reconocimiento del Derecho Internacional como un ordenamiento distinto al estatal ${ }^{31}$, cuyas determinaciones se imponen sobre el Derecho interno (KELSEN, VERDROSS). La clave del entendimiento de esa orientación del constitucionalismo, se concreta en el modo en que la propia Constitución admite la prevalencia del Derecho Internacional ${ }^{32}$.

Esta solución es una forma astuta y útil de mantener la soberanía del Estado materializada en su norma fundamental, al tiempo que se ratifica la prevalencia del Derecho Internacional. Esto, obviamente, no elimina la existencia de matices y posiciones intermedias, pero la clave común se encuentra en que cumplidos los requisitos constitucionales, el Derecho Internacional es plenamente aplicable y prevalente; y todo ello, sin que para que se produzca el desplazamiento de la norma estatal y sea

${ }^{28}$ Las teorías iuspositivistas fundamentan la juridicidad del Derecho Internacional en la voluntad del Estado, ya sea como una suerte de Derecho estatal externo (la voluntad exclusiva del Estado como única creadora de las normas internacionales: HEGEL), ya como expresión de la voluntad colectiva (sólo puede ser fuente del Derecho Internacional una voluntad común de varios Estados: TRIEPEL), ya por ser el propio Estado quien asume a modo de auto-limitación el cumplimiento del Derecho Internacional (G. JELLINEK).

29 Véase G. JELLINEK (1981: 296 y 300) y R. CARRÉ DE MALBERG (1998: 81).

${ }^{30}$ Las tesis normativistas, pero sobre todo las de calado iusnaturalista y sociológico, encuentran la fundamentación del orden jurídico internacional en una norma fundamental superior que le otorga validez (el Derecho de gentes en el caso de KELSEN), o bien en un hecho sociológico o psicológico, o bien en una justificación moral relacionada originalmente con la paz y la seguridad mundial.

31 Esto no quiere decir que con anterioridad no se hubieran asumido modelos monistas. El art. 4 de la Constitución de Weimar de 1919 disponía ya que «las reglas universalmente reconocidas del Derecho Internacional valen como parte integrante del Derecho alemán» (traducción propia). Inspirado en ese precepto, el art. 7 de la Constitución española de 1931 estableció lo siguiente: «El Estado español acatará las normas universales del Derecho internacional, incorporándolas a su Derecho positivo».

32 Para C. SCHMITT (2009): Teoría de la Constitución, Madrid: Alianza, 88, la Constitución crea el fundamento jurídico (auctoritas interpositio) de la validez estatal del Derecho Internacional. 
precisa la aprobación de actos normativos específicos en virtud de los cuales se proceda a la adaptación del Derecho interno al Derecho internacional convencional ${ }^{33}$.

Esta «interiorización» constitucional no soluciona, sin embargo, en qué términos se concretan las relaciones existentes entre las normas del Derecho interno y las de Derecho Internacional. Frente a quienes han explicado esas relaciones en términos de jerarquía, otras posiciones han abordado la prevalencia del Derecho Internacional en términos de responsabilidad internacional, sin que pueda hablarse de nulidad automática de las normas y actos internos contrarios a las obligaciones adquiridas en Derecho Internacional $^{34}$. Finalmente, han ido ganando fuerza aquellas tesis que se inclinan por la relación de competencia entre ordenamientos ${ }^{35}$.

La evolución de las posiciones que definen las relaciones entre Derecho estatal y Derecho Internacional permite mostrar que la disyuntiva Derecho estatal versus Derecho Internacional puede ser planteada, en última instancia, en términos de estricta aplicabilidad y no de validez ${ }^{36}$. La aplicabilidad de cualquier norma presupone su validez. Ordinariamente la norma que determina las condiciones de aplicación también establece los procedimientos para la generación de normas válidas. No obstante, la Constitución también puede remitirse a otras normas, las de Derecho Internacional. Sobre estas últimas, la Constitución no puede disponer sobre su validez, ya que su generación está regulada por el propio Derecho Internacional (Derecho de Tratados). Precisamente por ello, y siendo válidas de acuerdo con tales estándares, resultarán aplicables junto con las producidas mediante procedimientos internos regulados por la Constitución. Esto es, todas las normas aplicables son válidas, pero su validez puede originarse por dos vías: una, mediante procedimientos normativos diseñados por la propia Constitución; otra, mediante procedimientos regulados por normas independientes a las constitucionales. En este segundo caso, la Constitución deriva a otro sistema normativo la determinación de los presupuestos de validez de las normas internacionales.

El proceso descrito presenta al Derecho Internacional como un ordenamiento incompleto. El motivo es sencillo y se explica en virtud del que podemos denominar como proceso de «interiorización constitucional»: el ordenamiento internacional sólo adquiere plena efectividad en virtud del Derecho nacional, pues es éste el único ordenamiento que puede dotar de aplicabilidad a las normas internacionales. Cabría decir, en este sentido, que el ordenamiento jurídico nacional, presidido por la Constitución, se descompone en dos subsistemas normativos. El estrictamente nacional, que depende de la Constitución para producir normas válidas y también, lógicamente, para su

${ }^{33}$ M. DÍEZ DE VELASCO (1978: 159), J. A. PASTOR RIDRUEJO (2008: 172) o A. MARÍN LÓPEZ (1999): «Orden jurídico internacional y Constitución española», $R v$. de Derecho Político 45, 38.

${ }^{34}$ M. DÍEZ DE VELASCO (1978: 158 y 159) o J. A. PASTOR RIDRUEJO (2008: 171).

35 Defendida entre otros por I. DE OTTO (1995): Derecho Constitucional, Barcelona: Ariel, 126.

${ }^{36}$ Sigo a J. L. REQUEJO PAGÉS (1992): «Consideraciones en torno a la posición de las normas internacionales en el ordenamiento español», Rv. Española de Derecho Constitucional 34; y (1995): «Conjunción de sistemas normativos y reordenación del sistema de fuentes», Rv. de Estudios Políticos 90. 
aplicación; y, por otro lado, el subsistema internacional que sólo recibiría de la Constitución su aplicabilidad. Aquí se alza una diferencia sustancial con el Derecho Internacional Privado; aquí, no existe una alternativa real de aplicación del Derecho (Derecho Internacional versus Derecho Administrativo estatal). Una vez que el Estado presta su consentimiento para obligarse por medio de tratados conforme a la Constitución, no existe disyuntiva en la aplicación de normas y, por ello, no existe conflicto de normas alguno: únicamente es aplicable la norma internacional que desplaza a las normas internas en los términos establecidos en la Constitución de cada Estado.

Cosa distinta es que el contenido normativo de los acuerdos internacionales fuera en principio reducido y que, por ello, los Estados gozaran de amplias facultades normativas y ejecutivas para darles cumplimiento. Es decir, esa idea de desplazamiento a la que se acaba de aludir, tiene más sentido en épocas modernas. Situados en la primera mitad del siglo xx, el Derecho Internacional era fundamentalmente bilateral y, por ello, gozaba de un carácter transaccional más que puramente normativo $(\text { law-making })^{37}$. El fundamento de los acuerdos entre Estados era semejante al contractual, legitimado sobre la igualdad de las partes y los principios de reciprocidad y pacta sunt servanda. Acuerdos en los que, generalmente, los Estados parte gozaban de libertad para cumplir las obligaciones acordadas, sin perjuicio de la imposición de límites, o bien del veto de determinadas acciones. En definitiva, el contenido sustantivo de los acuerdos era relativo; desde luego no tienen parangón con los modernos tratados y convenios.

Esta apreciación debe servir para comprender que el Derecho Internacional y el Derecho Administrativo han evolucionado en planos sustantivos separados, como si cada uno le correspondiera una esfera regulativa distinta. Mientras el Derecho Internacional regulaba las relaciones entre Estados, y sólo puntual o excepcionalmente condicionaba sustantivamente al Derecho Administrativo, el Derecho Administrativo se resguardaba como instrumento regulatorio «ad intra», esto es, como orden normativo que estipulaba cómo se ejerce el poder en las relaciones ordinarias con los ciudadanos.

En el plano de la ejecución y aplicación de la norma, en coherencia con lo expuesto, se deduce con claridad que ésta dependía íntegramente de la Administración estatal. Este aspecto manifiesta la adaptación del Derecho Internacional a la territorialización estatal y, por ello, impide cualquier injerencia externa en los límites de su territorio para dar cumplimiento a los compromisos internacionales. El resultado siguiente es evidente: la segmentación de la sociedad internacional bajo el paradigma nacional estatalista.

No obstante, algunas situaciones excepcionales son detectables, aunque su fundamentación no altera la rigidez que la soberanía nacional atribuye a la ejecución del Derecho Internacional. La más evidente es aquella en la que, en virtud de compromi-

${ }^{37}$ J. H. H. WEILER (2016): «La geología del diritto internazionale: i paradigmi dell’amministrazione e della governance», L. TORCHIA (ed.), Atraversare i confini del diritto, Bolonia: Il Mulino, 233 y ss. 
sos internacionales, los Estados se comprometen a permitir la actuación de otros Estados en su territorio. Sería el caso, por ejemplo, de las Administraciones diplomáticas $^{38}$. Aquí, como advertíamos, el consentimiento prestado legitima que la norma sea aplicada por una autoridad extranjera ${ }^{39}$; es el propio Estado el que auto-limita su poder.

Estas reflexiones nos permiten obtener varias conclusiones: 1.) La Administración burocrática y jerarquizada, estrictamente territorial, representa una concepción de la Administración inescindiblemente ligada al proceso de consolidación de los Estados-nación ${ }^{40}$; sólo excepcionalmente la Administración nacional queda condicionada por el Derecho Internacional, por ejemplo, en la medida en que éste habilite puntualmente la actuación administrativa extranjera; y 2. a) La Administración aplica el Derecho Administrativo interno a toda persona situada en el territorio nacional, pues la nacionalidad es irrelevante a esos efectos. Esta última afirmación queda nuevamente excepcionada en los casos en que el Derecho Internacional resulte aplicable o condicione la aplicación del Derecho Administrativo nacional; en estos casos, el criterio territorial puede ser excepcionalmente sustituido por otro, por ejemplo, de naturaleza personal (caso del diplomático). En otras palabras, el Derecho Administrativo emplea un único criterio para su efectiva aplicación por la Administración nacional (el territorial), mientras que otros criterios como los de tipo personal, actúan en sentido negativo, esto es, como límites excepcionales de la aplicación del Derecho interno en virtud del Derecho Internacional.

\subsection{Conflictos de leyes y Derecho Internacional Privado.}

Si hubiera que llegar a una conclusión con las afirmaciones hechas hasta ahora, ésta sería que el principio de territorialidad no presenta apenas excepciones: la exclusividad del poder soberano impide injerencias en la regulación de las relaciones con los súbditos. Es más, allí donde pudiera detectarse alguna quiebra, la teoría jurídica

38 Éste es el ejemplo que maneja H. KELSEN (2007: 155).

39 G. JELLINEK (1981: 296 y 300) entendería que el principio de exclusividad descansa en la impenetrabilidad del Estado. Por ello, los actos soberanos en territorio ajeno serían un ejercicio de poder autorizado por otro Estado, con lo que tendrían el carácter de autolimitaciones del poder soberano. Por el contrario, desde su particular concepción del Derecho, para H. KELSEN (2007: 152-153) la llamada impenetrabilidad del Estado es falsa. Los actos de soberanía fuera del propio territorio pueden tener lugar por virtud del Derecho Internacional, de modo que puede hablarse de «la existencia de un Estado dentro del territorio de otro Estado extranjero».

40 Aproximaciones recientes a la cuestión en S. CASSESE (2013): «El surgimiento y el desarrollo del Estado Administrativo en Europa»; A. Von BOGDANDY y P. HUBER (2013): «Estado, Administración y Derecho Administrativo en Alemania»; y E. GARCÍA DE ENTERRÍA e I. BORRAJO INIESTA (2013): «Estado, Administración y Derecho Administrativo en España», todos en A. Von BOGDANDY y O. MIR (coords.), El Derecho Administrativo en el espacio jurídico europeo, Valencia: Tirant lo Blanch. 
ha elucubrado procesos de «domesticación» y sometimiento a la voluntad soberana estatal.

Así lo hemos mostrado en relación con el Derecho Internacional. Pero, ¿qué sucede con el Derecho interno de otros Estados? La respuesta encuentra aquí un desdoblamiento en función de que las relaciones jurídicas fueran estrictamente privadas o no.

En el plano jurídico-público, la respuesta ha de ser similar a la ya reiterada. Se podría decir que el principio de territorialidad y de exclusividad del Derecho estatal genera un efecto de indiferencia respecto de la validez y vigencia del Derecho extranjero. Ese efecto impide considerar la existencia de verdaderos conflictos entre normas nacionales ${ }^{41}$. Los motivos son claros: $\left.1 .^{\circ}\right)$ La exclusividad y unidad del ordenamiento impide la validez de cualquier otro Derecho (no hay un conflicto entre dos Derechos válidos); y 2..$^{\circ}$ La universalidad normativa del Estado le dota de normas completas materialmente que impiden la remisión a, y la aplicación de, cualquier otro Derecho.

En conclusión, el principio de territorialidad impide hablar de una óptica conflictual. Sólo desde una perspectiva laxa y puramente descriptiva cabría afirmar que el principio de territorialidad entraña una norma de conflicto general que redirige la solución de la colisión normativa al Derecho estatal. Esta afirmación en realidad muestra que la territorialidad del Derecho es la antítesis a las normas de conflicto.

La proyección del Derecho hacia el exterior ha encontrado su «espacio natural» en las relaciones sometidas al Derecho Privado. En este ámbito, el Derecho estatal admite la influencia que el Derecho de otros Estados puede tener en una misma situación o relación jurídico. Aquí no se trata de interferir en cómo otro Estado soberano regula y administra las relaciones con sus ciudadanos, sino de situaciones o relaciones jurídico-privadas específicas que tienen puntos de conexión con distintos territorios. De hecho, una aplicación estricta del principio de territorialidad podría dar lugar a la aplicación de dos ordenamientos distintos. Siendo esto así, la búsqueda de justicia en el caso concreto genera alicientes en los Estados para reconocer la vigencia «ad intra» del Derecho extranjero, siempre y cuando tenga lugar en condiciones de estricta reciprocidad ${ }^{42}$.

Tradicionalmente es aquí donde tienen lugar los conflictos de normas, pues aquí sí concurren distintas leyes válidas y vigentes susceptibles de aplicación sobre una misma situación o relación jurídica. De la gestión de la diversidad de los Derechos

${ }^{41}$ J-L. BERGEL (2006): Teoria Geral do Direito, Livraria Martins Fontes: Sao Paulo, 166, se refiere a este fenómeno como un «movimiento de disociación del Derecho en el espacio». Distinta es, como hemos expuesto, la extensión de efectos de un ordenamiento sobre acontecimientos acaecidos en otro Estado. Aquí no se plantea un conflicto entre normas válidas, sino una cuestión de pura efectividad de tales normas.

${ }^{42}$ H. NAWIASKY (2002: 97) y J-L BERGEL (2006: 182). 
nacionales y de la resolución de los conflictos de leyes derivada de ella, se ocupa el Derecho Internacional Privado ${ }^{43}$.

Los conflictos normativos presentan varios elementos caracterizadores. Desde el plano sustantivo, el Derecho Internacional Privado tiene por objeto regular relaciones jurídico-privadas en un contexto internacional ${ }^{44}$. El Derecho Internacional Privado es Derecho Privado y, por ello, responde a la lógica iusprivatista: la regulación de las conductas tiene una orientación «desde abajo» y está dirigida al reparto o distribución de derechos y deberes entre particulares. No en vano, se suele afirmar que quienes padecen directamente las consecuencias de las normas de Derecho Internacional Privado no son los Estados, sino los particulares implicados.

Por otro lado, estas relaciones tienen lugar en un entorno donde el legislador estatal se encuentra en una situación de concurrencia normativa con otros legisladores. La posición del legislador nacional no es «monopolística», sino concurrencial. Esto permite comprender que la «óptica» jurídica no pueda ser estrictamente nacional. Ahora bien, no por ello el Derecho Internacional Privado deja de ser Derecho estatal ${ }^{45}$. Esto pone de relieve que el Derecho estatal y el extranjero no están en una posición de igualdad, ya que sólo el Derecho interno puede habilitar la aplicación de una norma foránea ${ }^{46}$. La estatalidad del Derecho Internacional Privado se concreta, por tanto, en que es el Derecho del Estado el que regula los conflictos de normas.

¿Qué lugar ocupa aquí el principio de territorialidad y, más específicamente, el territorio? En primer lugar, lugar y en coherencia con lo recién expuesto, se deduce que el Derecho Internacional Privado evoluciona como un Derecho territorializado. Este factor incide en que las normas de conflicto hayan sido fundamentalmente está-

43 No en vano se suele calificar al Derecho Internacional Privado como un «Derecho para el Derecho» o un «Derecho para la aplicación del Derecho». Se trata de un «Derecho de colisión general» que abarcaría aquel conjunto de normas que, entre varios ordenamientos jurídicos simultáneamente vigentes, indica cuál va a aplicarse (Derecho de colisión atemporal). Véase, J. C. FERNÁNDEZ ROZAS (1986): «Sobre el contenido del Derecho internacional privado», Rv. Española de Derecho Internacional XXXVIII.

44 M. VIRGÓS SORIANO y F. J. GARCIMARTÍN ALFÉREZ (2004): «Estado de origen vs. Estado de destino. Las diferentes lógicas del Derecho internacional privado», Indret 4/2004; R. MICHAELS (2008b): «The New European Choice-of-Law Revolution», Tulane Law Rw 82(5); F. J. GARCIMARTÍN ALFÉREZ (2014): Derecho Internacional Privado, Madrid: Civitas-Thomson Reuters, 32 y 42-43; A. L. CALVO CARAVA y J. CARRASCOSA GONZÁLEZ (2014): Derecho Internacional Privado, tomo I, 15. a ed., Granada: Comares, 24 y ss.; o C. ESPLUGUES MOTA et al. (2015): Derecho Internacional Privado, 9. ${ }^{\mathrm{a}}$ ed., Valencia: Tirant lo Blanch, 81 y ss.

${ }^{4}$ Así, F. J. GARCIMARTÍN ALFÉREZ (2014: 36), A. L. CALVO CARAVA y J. CARRASCOSA GONZÁLEZ (2014: 9) o C. ESPLUGUES MOTA et al. (2015: 81 y ss.).

46 Como señala O. DUBOS (2010: 360), el carácter de Derecho nacional de la norma de conflicto permite cumplir formalmente con el principio de exclusividad. En los países anglosajones, esta orientación es consustancial a la doctrina de los derechos adquiridos de DICEY, en Inglaterra, y BEALE, en Estados Unidos. Su ingeniosa explicación serviría para salvar el dogma de la territorialidad de la Ley, llevándoles a afirmar que el juez nunca aplica un Derecho extranjero y que, cuando parece hacerlo, en realidad, se limita a reconocer y hacer ejecutar «vested rights» en otro país (R. MICHAELS: 2008b, 1610 y ss.). 
ticas y, por extensión, fundamentalmente territoriales. Aquí también cabe mantener la idea de adaptación del Derecho Internacional Privado a la segmentación estatalista, sólo superada con el proceso de europeización de las normas de conflicto.

Lo recién comentado explica que el territorio adquiera aquí también un papel central. Nos referimos ahora al papel del territorio en el Derecho Internacional Privado. Desde esta perspectiva, el territorio es utilizado como punto de conexión, es decir, como sede de las relaciones jurídicas en el espacio que permite vincularlas con un ordenamiento jurídico. La relevancia del territorio nada tiene que ver con la que se deriva del principio de territorialidad. Más allá de la intensidad de esta transformación, se ha de tener en cuenta que, en esta nueva vertiente, el territorio no asume un papel excluyente, sino todo lo contrario. En la concepción nacionalista de las reglas de conflicto, el territorio no sólo no constituye el punto de conexión único, sino que ni siquiera es el más importante para la solución de los conflictos de normas ${ }^{47}$. Desde esa perspectiva, el punto de conexión que adquiere mayor importancia es la pertenencia a una comunidad política (la nación) como realización del principio de la nacionalidad y la caracterización del estatuto personal de los ciudadanos como sujetos con derechos ${ }^{48}$.

Por último, la vertiente «nomológica». La clave en los conflictos de normas se encuentra en aplicar el Derecho que presenta vinculaciones más fuertes o relevantes, respetando el elemento de extranjería. En otras palabras, el Derecho Internacional Privado genera una especie de «conciliación» con los intereses particulares en proyección internacional. La técnica normativa para solucionar los conflictos de normas es específica, pues asume una tipología de normas incompletas o de carácter indirecto: son normas de remisión. La norma no regula la consecuencia jurídica aplicable al supuesto de hecho, sino que se limita a remitirse al ordenamiento aplicable que será el que ordene esas consecuencias. La clave, en definitiva, se encuentra en determinar el ordenamiento al que se encuentra sometida una situación o relación jurídica porque guarda una conexión íntima, su centro de gravedad o su sede natural (ya sea la Ley nacional o lex fori, ya la Ley extranjera o lex causae). Para concretar esa conexión, el Derecho identifica puntos de conexión del supuesto de hecho de la norma.

Las particularidades del Derecho Internacional Privado no se revelan aparentemente útiles para abordar la comprensión del Derecho Administrativo como Derecho estatutario del Estado. La utilidad se muestra casi por oposición, al menos desde el paradigma de la territorialidad del Derecho estatal. Sin embargo, hay dos aspectos que caracterizan al Derecho Internacional Privado que tienen relevancia para el propósito de este trabajo. El primero es que la regulación conflictual ordena relaciones

47 Donde persisten motivos de política u orden público, el territorio ha sido utilizado como punto de conexión determinante de la norma aplicable. El motivo es asegurar la aplicación de la lex fori en los asuntos en los que el Estado ejerce su soberanía y/o promueve la salvaguarda de determinados intereses generales.

48 E. RODRÍGUEZ PINEAU (2013): «Identidad y Nacionalidad», Anuario de la Facultad de Derecho de la UAM 17, 208-213. 
jurídicas horizontales y no verticales, es decir, entre sujetos privados y no entre el Estado y sus ciudadanos; el segundo es que lo hace con una orientación finalista: otorgar soluciones jurídicas justas en el caso concreto, en función de la mayor dependencia de las relaciones jurídicas con uno u otro ordenamiento. Como más tarde mostraremos, tanto la incorporación de técnicas normativas similares a las propias del Derecho Internacional Privado, como esa orientación «desde abajo» que fortalece las situaciones jurídicas de los particulares frente al poder público, constituyen dos elementos clave en el modo en que el Derecho Administrativo aborda las relaciones jurídicas transnacionales.

\section{LA PÉRDIDA DE CENTRALIDAD DEL PRINCIPIO DE TERRITORIALIDAD}

La fuerza explicativa del principio de territorialidad en el seno del Derecho se ha visto atenuada por la generalización de una serie de fenómenos de naturaleza socio-económica y de innata vocación supranacional que tienen lugar al albur del proceso de globalización. La superación del paradigma clásico de la territorialidad se constata en la progresiva disipación de los dualismos conceptuales derivados de la concepción clásica del principio de territorialidad: estatal versus supraterritorial; exclusividad del Derecho estatal versus relaciones interordinamentales; Derecho Público versus Derecho Privado.

La quiebra de estos dualismos tiene una incidencia determinante en el Derecho Administrativo: cercena su vocación de Derecho del Estado, para abrirse a la escena internacional; abre el ordenamiento jurídico estatal a relaciones con otros ordenamientos; aboca al Derecho Administrativo a incorporar a su esfera de interés regulativo la actuación de sujetos privados que ejercen funciones típicamente jurídico-administrativas o con relevancia jurídico-pública. Todo ello, como mostraremos posteriormente, abre el paso hacia una concepción del Derecho Administrativo construida desde los derechos de los ciudadanos y no desde la característica vis autoritaria.

La exposición que sigue expone el contexto en el que surgen los fenómenos jurídicos que originan nuestro análisis. La finalidad será mostrar cómo esa nueva realidad jurídica no es explicable desde ninguno de los pares conceptuales recién mencionados; muy al contrario, requiere una aproximación mixta y heterogénea. Se perfila una realidad jurídica, por tanto, peculiar, que precisa de una explicación jurídica particularizada.

\section{Superación de la exclusividad del Derecho estatal}

El título de este apartado podría sugerir que los procesos que vamos a describir se han producido sin la participación y a costa del Estado. Esta apreciación sería errónea, al menos, en el origen de ese proceso, así como en algunos estratos de su evolu- 
ción. Sobre esto último nos manifestaremos puntualmente en la exposición que sigue. Sí que dedicaremos una breve reflexión al protagonismo del Estado en el origen de esos procesos. En cuanto a esto, no se puede desconocer que la apertura del ordenamiento estatal a niveles supranacionales tiene su origen en el propio Estado. Son las Constituciones de postguerra las que incluso incorporarán mandatos (por ejemplo, nuestro art. 93) que tendrán como consecuencia la apertura definitiva del territorio hacia contextos internacionales. La trascendencia de la incorporación a la Unión Europea y la construcción de una Comunidad de Derecho ha ejercido una influencia determinante en el Derecho Administrativo. Algo similar podría afirmarse acerca del protagonismo de los Estados en el desarrollo de organizaciones internacionales y en la evolución de la normatividad del Derecho Internacional.

Los fenómenos que abordaremos a continuación se contextualizan y parten de ese marco. Ahora bien, como ya puntualizamos páginas atrás, la evolución de esos procesos nos sitúa en la actualidad en un escenario mucho más heterogéneo y cuya complejidad supera una explicación exclusivamente desde el paradigma estatalista.

\subsection{Fragmentación jurídica y «normas» (privadas) internacionales}

La post-modernidad post-westfaliana, como se ha venido a denominar por una parte de la doctrina, se caracteriza por la superación del Estado como sujeto integrador del poder público y fuente del Derecho válido ${ }^{49}$. El pluralismo institucional y jurídico es una consecuencia de la disgregación del poder más allá de la esfera estatal. A efectos expositivos se nos permitirá, primero, abordar el creciente pluralismo institucional, para, a continuación, afrontar el estudio del pluralismo jurídico.

El Estado comparte su tradicional protagonismo en la esfera internacional con heterogéneas manifestaciones institucionales con organización, composición, objeto y funciones diferentes, y con naturaleza público/privada híbrida. Esos nuevos actores gozan de calificaciones jurídicas diversas y poseen niveles de formalización variables ${ }^{50}$.

49 Este proceso se parece al descrito por P. GROSSI (1996: 281) al analizar el universo jurídico medieval. En ese sentido, M. R. FERRARESE (2000): Le istituzioni della globalizzazione, Bolonia: Il Mulino, 17; y J. FRIEDRICHS (2011): «When push comes to shove. The territorial monopoly of force and the travails of neomedieval Europe», M. BURGESS y H. VOLLAARD (eds.), State Territoriality and European Integration, Nueva York: Routledge, 231 y ss.

50 Sin ánimo de exhaustividad, cabe distinguir: $\left.1 .^{\circ}\right)$ Acuerdos multilaterales que se producen entre las grandes naciones desarrolladas, tales como el G-7 o el G-20; 2. ${ }^{\circ}$ ) Organismos constituidos por un conjunto de Estados encargados de la gestión de ámbitos específicos (OMC o FMI); $3 .^{\circ}$ ) Organizaciones públicas y privadas encargados de administrar los conocimientos técnicos y de adoptar disposiciones de normalización entre diversos sistemas (por ejemplo, la Unión Internacional de Telecomunicaciones, la Unión Postal Internacional o la Organización Mundial de Meteorología); $4^{\circ} .^{\circ}$ Agrupaciones empresariales (el Comité Marítimo Internacional, la IATA, la International Federation of Consulting Engineers (FIDIC), la London Corn Trade Association o el Organisme de Liaison des Insdutries Métalliques Européenes); etc. 
Sí coinciden, no obstante, en disponer de un expertise fundamental en los concretos sectores de actividad en los que intervienen que son, lógicamente, concurrentes con los propios de sus miembros. El escenario internacional se heterogeneiza desde el punto de vista subjetivo ${ }^{51}$.

A las relaciones existentes entre los distintos sujetos de la escena internacional no les son trasladables sin más los principios clásicos del Derecho Internacional Público. Asumen el protagonismo nuevos principios que, al tiempo que dirigen la actuación multilateral (principios de gobernanza multinivel cooperativa, público-privada, formal/informal ${ }^{52}$ ), contribuyen a generar nuevas fuentes de legitimación ante la pérdida de una base democrática. El nuevo contexto internacional se caracteriza por seguir la lógica del «networking» ${ }^{53}$, es decir, una lógica multirrelacional, acéntrica y heterárquica, en las antípodas del proceso unidimensional de actuación del centralismo estatal ${ }^{54}$.

Debemos insistir, nuevamente, en que esto no quiere decir que, en el nuevo contexto internacional, el Estado haya perdido su relevancia. Lo cierto es que su papel sigue siendo importante, aunque ahora compartiendo protagonismo con nuevos actores. Esa pérdida de relevancia se ve compensada con un incremento del poder cooperativo transnacional, en la medida en que siguen siendo los Estados quienes suelen mantener el control en la selección, coordinación y regulación de los sujetos que asumen las «cesiones» del poder estatal en los procesos de globalización ${ }^{55}$.

Parejo a ese pluralismo institucional en la escena internacional, se consolida un cada vez más intenso pluralismo jurídico ${ }^{56}$. Buena parte de los nuevos sujetos

51 Sobre esta cuestión en el marco del Derecho Internacional, véase C. IZQUIERDO SANS (2005): «Algunas respuestas del Derecho Internacional a la globalización», Anuario de la Facultad de Derecho de la $U A M$ 9. En el contexto del Derecho Administrativo Global y del Derecho Administrativo Internacional pueden consultarse B. KINGSBURY et al. (2005): «The Emergence of Global Administrative Law», New York University Public Law and Legal Theory Working Papers 17, y E. SCHMIDT-ASSMANN (2006): «La ciencia del Derecho Administrativo ante el reto de la internacionalización de las relaciones administrativas», $R v$. de Administración Pública 171, como obras de referencia. En general, sobre este tema M. R. FERRARESE (2000: 101 y ss.) o J. E. FARIA (2001): El Derecho en la Economía Globalizada, traducción del original en portugués de 1999, Madrid: Ed. Trotta, 127 y ss.

52 Para D. McKEE (2010): «Review Essay - Emmanuel Melissaris’s Ubiquitous Law: Legal Theory and the Space for Legal Pluralism», Comparative Research in Law E Political Economy 36, 6: "From the perspective of legal theory, governance is presented as a synthesis, overcoming the binary oppositions that had dominated legal thought throughout the 20th century, such as public/private, form/substance, and regulated/unregulated».

${ }_{53}$ Esta perspectiva es mantenida por los autores del Derecho Administrativo Global. Por todos, B. KINGSBURY et al. (2005) o J-B. AUBY (2012: 210 y ss.).

54 K-H. LADEUR (2010: 4, 10-11).

55 Asume este planteamiento P. MERCADO PACHECO (2005: 147 y ss.). Relacionado con ello, la doctrina alemana maneja la noción de «estatalidad abierta» para referirse al protagonismo del Estado en la creación del Derecho Administrativo Internacional (E. SCHMIDT-ASSMANN: 2006, 21 y ss.).

56 Sobre la fragmentación jurídica, véase M. R. FERRARESE (2000: 101 y ss.), J. E. FARIA (2001: 127 y ss.) y A. FISCHER-LESCANO y G. TEUBNER (2004): «Regime-Collisions: The Vain Search for Legal Unity in the Fragmentation of Global Law», Michigan Journal of International Law 25. D. McKEE 
de la escena internacional dictan directrices, recomendaciones, guías, normas, reglamentos, etc., con eficacia vinculante variable ${ }^{57}$, refrendada por la autoridad que les concede la independencia y/o la especialización que suele caracterizar a esos sujetos $^{58}$. Aquí cabe observar un fenómeno de «externalización» y pérdida del expertise de los Estados. En contextos de globalización, el objeto de la ordenación que puede abordar el Derecho Administrativo no sólo trasciende de los intereses públicos, sino que también puede concernir aspectos estrictamente privados. El carácter poliédrico de las materias, tanto por la suma de intereses y actores en juego, como por la dimensión de su alcance y efectos, unido a la especialización y tecnificación de muchas de ellas, genera una situación de desbordamiento de la capacidad estatal para afrontar su completa y satisfactoria regulación. Esas capacidades, sin embargo, las adquieren aquellas organizaciones especializadas. Se producen, de este modo, flujos de información asimétricos que perjudican a quienes carecen de los conocimientos especializados, ya que progresivamente pierden el control sustantivo de la materia, hasta llegar incluso a depender de aquellas fuentes de ordenación extrajurídicas.

Otros efectos pueden igualmente detectarse. La creación de ese Derecho no estatal es cada vez más especializado y sectorizado, de lo que cabe deducir una incidencia negativa en la sistematización del ordenamiento jurídico ${ }^{59}$. Añadidamente, este efec-

(2010: 7), afirma al respecto: «... legal pluralism merely signifies the recognition of multiple legalities — as opposed to legal monism (...). But in its modern form, legal pluralism has mainly been used to challenge state-centered accounts of law».

57 Nos referimos a fenómenos como la selfregulation. P. A. De MIGUEL ASENSIO (2001): «El Derecho Internacional privado ante la globalización», Anuario Español de Derecho Internacional Privado 1, pone ejemplos en sectores del comercio internacional, en relación con organizaciones heterogéneas de operadores comerciales como el Comité Marítimo Internacional, la IATA, la FIDIC, la London Corn Trade Association o el Organisme de Liaison des Insdutries Métalliques Européenes. Esas normas tienen incidencia en la actividad de organizaciones internacionales que en otro tiempo elaboraban convenios internacionales; es el caso de UNIDROIT que, en materia contractual, ahora elabora instrumentos cuya eficacia se subordina a que las partes prevean su eventual aplicación. Nos referimos, por tanto, a la aprobación de «normas» dictadas por organizaciones de naturaleza mixta o privada que, a pesar de tener eficacia orientativa o recomendatoria, son asumidas por las Administraciones estatales en virtud de su sustento científico-técnico, consensuado y económicamente eficiente. A. FISCHER-LESCANO y G. TEUBNER (2004: 1009 y ss.) llegan a hablar de la creación de «autonomous "private” legal regimes».

58 A pesar de ser crítico con el «soft law» como vehículo para realizar el ideal del imperio de la Ley, F. J. LAPORTA SAN MIGUEL (2005: 194) reconoce que muchos de los instrumentos en que se contiene el «soft law» «suelen estar dotados de cierta "auctoritas"por su elaboración independiente y experta, de forma que inadvertidamente invierten la carga de la prueba, y aquellos Estados, organismos, agencias o corporaciones que no los adoptan se ven obligados a justificar públicamente su desacuerdo».

Un magnífico ejemplo de este fenómeno es el de los organismos de estandarización internacional. Mientras que en algunos ámbitos estos organismos ejercen sus funciones en competencia, en otros ejercen un monopolio de la producción de estándares internacionales, en una suerte de delegación de la autoridad regulatoria en el ámbito global que recae en organismos públicos, pero también en otros totalmente privados y cuyos destinatarios son los Estados y los particulares.

59 J. E. FARIA (2001: 115 y ss.). 
to se confirma porque las nuevas fuentes normativas entablan relaciones con los distintos ordenamientos nacionales, pero esas relaciones tienen lugar en un marco de ausencia de jerarquías normativas y de criterios jurídicos ordenadores claros. Surgen así colisiones de normas cuya solución no responde con exactitud a ninguno de los criterios clásicos.

La fragmentación jurídica supone, en definitiva, la quiebra de la lógica iuspositivista que vincula la dependencia del Derecho a la existencia del Estado ${ }^{60}$. El Derecho no sirve ya (sólo) a las necesidades del poder soberano, sino también a las de otros poderes (económicos) que crean sus propias normas para autorregularse o para regular los sectores de su interés. Podría decirse que la superación de la relación unidireccional Estado-Derecho, es el resultado de la necesidad de un Derecho adaptado al mercado. Lógicamente esto también implica la tendencial inversión de la primacía Derecho-Economía.

De lo antedicho se deduce con facilidad que las relaciones jurídicas que se entablan en el contexto global no pueden ser ordenadas íntegramente por el Derecho estatal. Se caracterizan por la hibridación jurídica. Esta idea se ha intentado sintetizar con la calificación de relaciones «diagonales», manifestación típica de las relaciones jurídicas transnacionales en sentido amplio. Recordemos que estas tesis emplean el calificativo transnacional para referirse a heterogéneas realidades jurídicas que se caracterizan por la combinación de lo nacional y lo supraterritorial, lo público y lo privado y, por último, la colisión entre órdenes normativos ${ }^{61}$. En coherencia con esta premisa, la utilización del calificativo «diagonal» pretende superar el recurso a calificativos como relaciones verticales u horizontales, pero también relaciones jurídico-públicas y jurídico-privadas, para introducir la idea de interconexión (nacional/internacional-público/privado) y de indiferencia por la localización territorial $^{62}$.

${ }^{60}$ Como expusiera P. GROSSI (1996: 282-283) respecto del pluralismo medieval, ahora también cabe hablar de «un diritto senza Stato». Según D. McKEE (2010: 6-7): «State and non-state forms of law and regulation are interpenetrated and mutually constitutive». S. W. SCHILL (2015): «Abordagens jurídicas transnacionais sobre direito administrativo: a conceituação dos contratos públicos na globalização», Rv. de Direito Administrativo 268, 30, lo expresa del siguiente modo: «O direito internacional influencia o direito administrativo nacional; o direito nacional retroalimenta os regimes internacionais; as ideias sobre o direito administrativo nacional ultrapassam as fronteiras dos países e são influenciadas pelas atividades de elaboração de normas dos agentes públicos e privados. Todos esses processos integram o direito administrativo em um espaço jurídico transnacional».

61 En esta línea, FISCHER-LESCANO y G. TEUBNER (2004); M. EVERSON y C. JOERGES (2006): «Re-conceptualising Europeanisation as a public law of collisions: comitology, agencies and an interactive public adjudication», H. C. H. HOFMANN y A. H. TÜTK, EU Administrative Governance, Cheltenham: Edward Elgar; C. JOERGES (2010): «A New Type of Conflicts Law as the Legal Paradigm of the Postnational Constellation», C. JOERGES y J. FALKE (eds), The Social Embeddedness of Transnational Markets, Oxford: Hart Publishing, 2; o K-H. LADEUR (2010).

62 En palabras de J-B. AUBY (2012): La Globalización, el Derecho y el Estado, Sevilla: Global Law Press, 52, la globalización ejerce una presión tendente al desarrollo de normas y mecanismos jurídicos «indiferentes a la localización espacial de los objetos a los que se aplican». 


\subsection{El Derecho Administrativo es Derecho Internacional y viceversa.}

El Derecho Administrativo desborda el territorio de los Estados generando el efecto de la ya mencionada desterritorialización del Derecho Administrativo ${ }^{63}$. El Derecho Administrativo ya no se limita a ser un Derecho doméstico con validez y eficacia interna ${ }^{64}$, sino que constituye un Derecho que se expande en ámbitos tradicionalmente propios del Derecho Internacional. El proceso contrario también tiene lugar con creciente intensidad: cada vez es más común que el Derecho Internacional Público descienda a incidir sobre aspectos calificables como cuestiones internas.

La doctrina de raíz americana del Derecho Administrativo Global y la doctrina de origen alemán del Derecho Internacional Administrativo han abordado esas interconexiones existentes entre Derecho Administrativo y Derecho Internacional Público ${ }^{65}$. Estas interconexiones se manifiestan de diversas maneras, pero de forma sintética podrían concretarse en dos modos. El primero, muestra la expansividad del Derecho Administrativo, en especial, del Derecho de organización. En todas las esferas internacionales se detecta la creación de órganos de gestión y administración, así como la instauración de procedimientos de toma de decisiones. Ese orden normativo alumbra la existencia de un Derecho Administrativo organizativo que ordena tanto la actividad de las instituciones creadas, como mecanismos cooperativos horizontales y verticales ${ }^{66}$.

El segundo aspecto a destacar respondería al proceso contrario, esto es, a la incidencia interna del Derecho Internacional ${ }^{67}$. Cada vez es más frecuente que las fuentes

${ }^{63}$ Como señala E. SCHMIDT-ASSMANN (2006: 9), «la internacionalización de la Administración se caracteriza, así, por una pérdida de territorialidad. Si se tiene en cuenta que el principio de territorialidad ha sido siempre uno de los axiomas “clásicos” del Derecho administrativo».

${ }^{64}$ Coincidiendo con J-B. AUBY (2012: 53 y 149 y ss.), esto no significa que la desestatalización del Derecho suponga que el Derecho Administrativo funcione al margen del Estado, sino que éste tiene un menor control sobre él, implicando una regresión en la centralidad jurídica del Estado.

65 Sobre Derecho Administrativo Global, véase M. SHAPIRO (1993): «The Globalization of Law», Indiana Journal of Global Legal Studies 1(1); C. HARLOW (1998): «European Administrative Law and the Global Challenge», RSC Working Paper 98/23; S. CASSESE (2005a): "Global Standards for National Administrative Procedure», Law and Contemporary problems 68; (2005b): «Administrative Law without the State? The Challenge of Global Regulation», New York University Journal of International Law and Politics 37; (2005c): "The Globalization of Law», New York University Journal of International Law and Politics 37; B. KINGSBURY et al. (2005); S. BATTINI (2006) o J-B. AUBY (2012). Sobre Derecho Administrativo Internacional, E. SCHMIDT-ASSMANN (2006) y P. DANN y M. V. ENGELHARDT (2011): «The Global Administrative Order Through a German Lens: Perception and Influence of Legal Structures of Global Governance in Germany», German Law Journal 12(7).

${ }^{66}$ E. SCHMIDT-ASSMANN (2006: 20 y ss.). M. CARDUCCI (2014): «Una riflessione sulla utilità della semantica di Otto Hintze nel cosiddetto "cambio di paradigma” del diritto amministrativo", Rv. Digital de Direito Administrativo 1(2), 288, afirma, en este sentido, que "il "condominio" dell'Administrative Global Law si fonda sulla erosione della sovranità quale limite di una sconfinata Rule of Market, in funzione della quale ri-costruire procedimenti e processi».

${ }^{67}$ S. BATTINI (2006: 8): «International law is increasingly able to penetrate state borders: it is now less concerned with the relationships between governments, and much more interested in governments' actions on their own territory». En una dirección similar, J. H. H. WEILER (2016: 253 y ss.). 
del Derecho Internacional prevean dos tipos de mecanismos: de control y de sustitución $^{68}$. En cuanto a los primeros, el Derecho Internacional reconoce que las autoridades de los Estados soberanos tienen el poder de adoptar de manera autónoma normas y decisiones; ahora bien, el ejercicio de esas facultades está sujeto a condiciones cuyo cumplimiento es supervisado por las organizaciones internacionales. En cuanto a los mecanismos de sustitución, el Derecho Internacional limita parcialmente el poder de las autoridades nacionales para determinar el contenido de las disposiciones aplicables a nivel nacional, estando los poderes públicos nacionales obligados a adoptar y poner en práctica normas aprobadas a nivel internacional. La expansividad del Derecho Internacional explica que haya incluso quienes afirmen que el futuro del Derecho Internacional es doméstico ${ }^{69}$.

La desterritorialización del Derecho nos muestra que hay Derecho Administrativo en lo nacional y en lo internacional, y desde luego también lo hay en el Derecho Europeo, al igual que hay Derecho Internacional en el Derecho Europeo y en el nacional.

\subsection{Relaciones entre ordenamientos estatales}

Una fase característica del proceso de desterritorialización del Derecho, con especial intensidad en el contexto de europeización del Derecho Administrativo ${ }^{70}$, es aquella en la que los ordenamientos estatales se abren horizontalmente a relaciones con el ordenamiento de otros Estados. Pongamos esta afirmación en contexto.

El espacio jurídico europeo es concebido como la base de un sistema jurídico complejo y abierto ${ }^{71}$ que no posee un territorio propio en sentido estricto, pero que se concreta sobre un ámbito supranacional ${ }^{72}$. El concepto de «supranacionalidad»es

68 S. BATTINI (2006: 8 y ss.).

69 Tomo la expresión de A A-M. SLAUGHTER y W. BURKE-WHITE (2006): «The Future of International Law is Domestic», Harvard International Law Journal 47, 331-333. Siguen esta tesis R. MICHAELS (2008a): «Public and Private International Law: German views on Global Issues», Journal of Private International Law 4(1), 122 y 123, K-H. LADEUR (2010: 9) y J-B. AUBY (2012: 64 y 233).

70 En este trabajo no podemos ahondar en la europeización del Derecho Administrativo. Véase J. AGUDO GONZÁLEZ (2013): «Sobre la europeización del Derecho y la evolución de la teoría del procedimiento administrativo», $R v$. de Derecho Europeo 45.

71 A. Von BOGDANDY (2016): «La transformación del derecho europeo, el concepto reformado y su búsqueda de la comparación», $R v$. de Derecho Comunitario Europeo 54, 461, sintetiza perfectamente esta idea, entendiendo la noción de espacio jurídico como alternativa a ordenamiento. Tras esta noción se encuentra la idea de relación y mutua dependencia entre ordenamientos (nacionales y europeo), como algo distinto a la fusión de ordenamientos en uno solo.

72 El nuevo paradigma administrativo se desenvuelve en el «espacio jurídico europeo» que proclama el art. 3.2 del TUE, cuando dispone que la Unión Europea constituye «un espacio de justicia sin fronteras interiores». En opinión de G. della CANANEA (2007): «Dal territorio statale allo spazio giuridico europeo», M. CAMMELLI, Territorialità e delocalizzazione nel governo locale, Bolonia: Il Mulino, 67-69, la noción de «espacio» no sustituye a la relación inherente entre Estado, poder soberano y 
la alternativa conceptual utilizada para definir el ejercicio de poder público pro unione que es imputable a las instituciones, agencias y órganos europeos, distinto, por tanto, tanto al ejercicio de poder soberano en el territorio de cada Estado, como al enmarcado en el seno de las relaciones sometidas al Derecho Internacional ${ }^{73}$.

La ejecución del Derecho Europeo no cuenta con una organización administrativa propia y plena como pudiera disponer cualquier Estado. Por la propia idiosincrasia de la Unión Europea, recurre a la construcción de una Administración cooperativa en la que se integran organizaciones y órganos estrictamente europeos, juntamente con otros mixtos, así como con otros estrictamente nacionales, cuando no directamente remite la ejecución del Derecho Europeo a las Administraciones nacionales (ejecución indirecta). Esta afirmación permite atisbar el amplio abanico de actuaciones administrativas de rango supranacional que tienen lugar en el seno del espacio jurídico europeo ${ }^{74}$.

Este modelo de integración muestra otra vertiente del ejercicio de poder público a nivel supraterritorial, a pesar de estar conferido a autoridades nacionales. Aquí se localizan fenómenos jurídicos transnacionales articulados mediante la técnica del reconocimiento mutuo ${ }^{75}$. Esta técnica se articula entablando relaciones entre ordenamientos estatales y, consecuentemente, conexiones cooperativas entre las Administraciones nacionales; y todo ello, con un fin: optimizar la efectividad del ejercicio de las libertades comunitarias, sin perjuicio de otros fines ampliados progresivamente por la expansión del reconocimiento mutuo a otros ámbitos.

Debemos insistir en que la proyección del Derecho Administrativo en estos casos no es vertical, sino horizontal. Estos fenómenos jurídicos ponen de relieve la incapacidad del Derecho Administrativo estatal para regular de forma completa las relaciones jurídicas que entablan sus ciudadanos en un contexto supranacional ${ }^{76}$. La superación de esas limitaciones no se sustituye por una armonización de legislaciones, sino con la proyección del Derecho estatal hacia otros ordenamientos nacionales, generando conexiones que conjuntamente permiten una regulación plena ${ }^{77}$.

territorio, ya que la Unión Europea, al no ser un Estado, no tiene territorio propio. Lo constituido por los Tratados es un «espacio jurídico» en el que la Unión Europea puede desarrollarse.

73 Véase, H. C. H. HOFMANN (2008): «Mapping the European Administrative Space», West European Politics 31(4), o R. SCHÜTZE (2009): «On "Federal” Ground: The EU as an (Inter)National Phenomenon», Common Market Law Rw 46.

74 Véase J. AGUDO GONZÁLEZ (2014): «La Administración del espacio administrativo europeo», Rv. Vasca de Administración Pública 99-100.

75 S. CASSESE (2005c: 981); B. G. MATTARELLA (2011): «The Influence of European and Global Administrative Law on National Administrative Acts», E. CHITI y B. G. MATTARELLA (eds.), Global Administrative Law an EU Administrative Law, Springer-Heidelberg: Springer, 70; o J. AGUDO GONZÁLEZ (2015): «La Administración del reconocimiento mutuo. Un análisis a partir de la libre circulación de profesionales... hasta la unidad de mercado», Rv. de Administración Pública 197.

76 S. BATTINI (2006: 8).

77 La proyección horizontal es parte de la idea de permeabilidad entre sistemas jurídicos de J-B. AUBY (2012: 127 y ss.), que recupera para el contexto europeo A. Von BOGDANDY (2016: 452).

N. ${ }^{\circ} 103$, septiembre-diciembre 2018, págs 155-190 


\section{Superación de la división Derecho Público versus Derecho Privado/Derecho Internacional Público versus Derecho Internacional Privado}

Los límites entre Derecho Público y Derecho Privado son cada vez más difusos, produciéndose extensiones y retraimientos recíprocos ${ }^{78}$. Ni los elementos institucionales, ni las fuentes normativas, ni las materias sustantivas, son ya patrimonio del Derecho Público o del Derecho Privado.

Este escenario de recíproca influencia público-privada encuentra una especial manifestación en la relación entre Derecho Internacional Público y Privado. No es infrecuente encontrar opiniones que afirman que asistimos a una fusión de ambas disciplinas, cuando no a la absorción del Derecho Internacional Privado por el Derecho Internacional Público ${ }^{79}$. El motivo que justificaría esa tesis es la producción intensa de un Derecho convencional uniforme que incide directamente en la singularidad normativa que ha servido para justificar la autonomía científica del Derecho Internacional Privado (normas de conflicto) y que, añadidamente, contribuye a superar la concepción estatista que en origen definiera al Derecho Internacional Privado ${ }^{80}$.

Frente a esta tendencia relativa a la fusión de Derecho Internacional Público y Derecho Internacional Privado por efecto de la expansión del primero, hay quienes han advertido de un efecto en sentido opuesto ${ }^{81}$. El Derecho Internacional Público tradicionalmente ha abordado las relaciones entre Estados, dejando las relaciones entre privados y las cuestiones económicas al Derecho Internacional Privado. Sin embargo, ahora que las empresas multinacionales y los individuos como titulares de derechos han entrado como actores del nuevo escenario del Derecho Internacional Público, esta distinción se vuelve menos clara. Esto es aún más evidente, si consideramos que el Derecho Económico Internacional se ha convertido en un elemento central del Dere-

${ }^{78}$ N. BOBBIO (2006: 30-32) describía ya esa misma circunstancia constatando dos procesos inversos: la «publificación de lo privado» y la «privatización de lo público». Una aproximación general al tema en J-B. AUBY (2012: 220 y ss.) y, sobre todo, en L. CASINI (2013): «Down the Rabbit Hole: The Projection of the Public/Private Distinction Beyond the State», Jean Monnet Working Paper 8.

79 Acerca de estos planteamientos, véase P. A. De MIGUEL ASENSIO (2001).

80 El sistema conflictual tradicional basado en el criterio de la nacionalidad y el territorio soberano, se ve complementado con un sistema de conexión territorial más flexible (domicilio o residencia habitual) y/o fundado en la autonomía de la voluntad privada. En esa dirección de reforzamiento de la autonomía de la voluntad, R. MICHAELS (2008a: 131-132) se pregunta, «what exactly is the role of human rights in private international law? Citando la jurisprudencia del TJUE, recuerda que el Tribunal «has invoked rules against discrimination in the law of family names. This could eventually make it necessary to replace nationality as a connecting factor by habitual residence». El autor se refiere a la STJUE de 16 de julio de 2009 (as. 148/02, García Avello). La clave está, lógicamente, en la prohibición de discriminación por razón de la nacionalidad en un contexto como el europeo. Véase, E. RODRÍGUEZ PINEAU (2013: 222 y ss.).

${ }^{81}$ R. MICHAELS (2008a: 138) pone en duda la influencia del Derecho Internacional Público sobre el Derecho Internacional Privado: «the thesis that public and private international law are necessarily merging is not substantiated. Instead, private international law is expanding its scope». 
cho Internacional Público y es cada vez más habitual que el Derecho Internacional Público utilice el lenguaje técnico tradicionalmente reservado al Derecho Internacional Privado. Por estos motivos, aun admitiendo la expansión del Derecho Internacional Público, lo cierto es que esa expansión se estaría produciendo paradójicamente no a costa del Derecho Internacional Privado, sino a costa del carácter «público» del Derecho Internacional Público.

Esa «prevalencia» creciente de lo privado y del Derecho Internacional Privado tiene efectos directos en el Derecho Administrativo. El Derecho Administrativo no es indiferente a las influencias externas provenientes de las dinámicas económicas internacionales ${ }^{82}$. Los mismos fenómenos jurídicos que permiten hablar de dinámicas «iusprivatizadoras» en el Derecho Internacional, habilitan trasladar esa misma afirmación a un Derecho Administrativo desterritorializado ${ }^{83}$. Ese efecto «iusprivatizador» se traslada al Derecho Administrativo mediante los incipientes Derecho Administrativo Global/Derecho Administrativo Internacional, pero también por el Derecho Europeo y por obra de la incidencia interna del Derecho Internacional Público. Esto, como más adelante se concretará, tiene repercusiones relevantes en la concepción del Derecho Administrativo que se deriva de esos procesos de transformación.

El fenómeno opuesto (efectos «iuspublificadores» del Derecho Privado) también ha sido descrito por la doctrina. Una primera y principal consecuencia de ese fenómeno es la extensión de la aplicación de principios del Derecho Público a agentes, actores u operadores privados. Un objetivo del Derecho Administrativo Global es trasladar a la globalización jurídica las exigencias del Estado de Derecho ${ }^{84}$ o, probablemente, con más corrección del Rule of $L a w^{85}$. Claro está que otra forma de abordar este resultado es entender que los principios del Estado de Derecho no son ni Derecho Público, ni Derecho Privado, sino mandatos optimizables con formas de Derecho Público y/o de Derecho Privado, siendo indiferente quiénes sean los destinatarios de las normas.

${ }^{82}$ En opinión de G. NAPOLITANO (2014: 49), el Derecho Administrativo también se apoya, con diferentes expresiones, en la «oferta jurídica» que brinda el Derecho Privado. Algunos de esos efectos ya han sido puestos de relieve en J. AGUDO GONZÁLEZ (2015: 379 y ss.) para el contexto europeo.

${ }_{83}$ En esta dirección, C. HARLOW (1998) afirma: «In systems which recognise a sharp public/ private distinction, the very foundations are shaken, as the worth of the basic distinction comes into question». Por su parte, K-H. LADEUR (2010: 15) considera que el Derecho global «can no longer be described in the classic sense as "public law" but stands in a corresponding relationship to transnational private law ("lex mercatoria" of a new sort and other forms of neo-spontaneous law)».

${ }^{84}$ E. SCHMIDT-ASSMANN (2006: 28 y ss.), B. KINGSBURY (2009): "The Concept of "Law" in Global Administrative Law», The European Journal of International Law 20(1), D. M. TRUBEK (2009): O novo direito e desenvolvimento: presente, pasado e futuro, J. RODRIGO RODRIGUEZ (org.), Sao Paulo: Saraiva, 185 y ss., o J-B. AUBY (2012: 177-180), confirman esa tesis desde perspectivas diferentes.

${ }^{85} \mathrm{Si}$ una consecuencia puede derivarse del proceso de globalización, es una tendencial «americanización» del Derecho, aunque quizá no tan pronunciada como anunciara M. SHAPIRO (1993). 
Otra manifestación de este último fenómeno es la intensificación de la aprobación de normas vinculantes de Derecho Internacional Público que tienen como finalidad homogeneizar y unificar mediante «códigos» las relaciones comerciales jurídico-privadas. En el Derecho Mercantil se advierte una transición desde un sistema conflictual basado en la preferencia de la Ley nacional, hacia un sistema con vocación de universalidad (Derecho Comercial Internacional) ${ }^{86}$. La necesidad de uniformidad y, por tanto, de previsibilidad de la legalidad de las conductas de las partes de un contrato, favorece la generación de un Derecho uniforme y común, susceptible de aplicación sin referencia a las fronteras nacionales. Éste es, de hecho, uno de los elementos determinantes en la globalización económica. Ahora bien, esta lógica de los «códigos» universales no es precisamente la iusprivatística. Podría decirse, de hecho, que todos esos procesos de «codificación» internacional no son más que la manifestación de una tendencia hacia la «toma de control» de las relaciones privadas con parámetros ordenadores iuspublicistas ${ }^{87}$.

\section{CONSIDERACIONES FINALES: \\ EL «CARÁCTER RELACIONAL» DEL DERECHO ADMINISTRATIVO DE LA TRANSNACIONALIDAD}

\section{De la exclusividad y la complitud del Derecho Administrativo estatal a las relaciones interordinamentales y la conflictualidad}

El Derecho Administrativo ordena fenómenos jurídicos transnacionales con base en elementos jurídicos diferenciales y contrapuestos con los deducibles del paradigma territorial del Derecho Administrativo: el carácter exclusivo, pleno y estático del Derecho Administrativo estatal ${ }^{88}$, se contrapone a un Derecho Administrativo compartido, basado en relaciones interordinamentales y dinámico.

Esta realidad jurídica pone de relieve que el Derecho Administrativo dejó de ser sólo Derecho Administrativo estatal. El Derecho Administrativo de la transnacionalidad o transnacional es Derecho Administrativo estatal, pero al mismo tiempo es Derecho Europeo y Derecho Internacional. Esto se explica porque el efecto primordial de la transnacionalidad es la instauración necesaria de relaciones entre órdenes jurídicos.

86 Véase J. FERNÁNDEZ ROZAS (2000) y R. ILLESCAS ORTIZ (2005: 82 y ss.). El último autor, en p. 85, afirma que «la dimensión geográfica de su vigencia (se refiere a ese Derecho Comercial Internacional) ha de ser global cuanto menos tendencialmente sin que pueda quedar reducido a un mero ámbito regional».

${ }^{87}$ Esta sugerente idea en P. GROSSI (1996: 272-273), aunque para un contexto diferente. En sentido similar, S. CASSESE (2005c: 980).

88 A. Von BOGDANDY (2016: 451) lo expresa perfectamente: «el Derecho interno constituía un sistema cerrado, autosuficiente de comunicación jurídica». 
El Derecho Administrativo transnacional evidencia la incomplitud del Derecho estatal para ordenar íntegramente las relaciones jurídico-administrativas. Frente a la exclusividad del Derecho estatal dimanante de la soberanía del Estado y del principio de territorialidad, los fenómenos jurídicos transnacionales nos muestran que los ordenamientos nacionales entablan relaciones con otros órdenes normativos para culminar el régimen de esas relaciones jurídicas. Esto obliga a superar el pensamiento jurídico basado en la sistemática del ordenamiento jurídico, para abrirse a un pensamiento relacional ${ }^{89}$. En este sentido, el Derecho Administrativo comienza a interiorizar un modelo conflictual que recuerda a la técnica normativa del Derecho Internacional Privado. Cabe detectar varios modelos.

En el marco de las relaciones horizontales entre ordenamientos nacionales, el reconocimiento mutuo incorpora la óptica conflictual con rasgos diferenciales ${ }^{90}$. Una

89 Esta perspectiva no se agota con la de carácter conflictual que vamos a abordar. Una visión original en esta línea ya en G. ROBLES MORCHÓN (2007): Pluralismo jurídico y relaciones intersistémicas, Madrid: Thomson-Civitas. Para el espacio jurídico europeo, A. Von BOGDANDY (2016: 461) afirma que el Derecho Europeo «mantiene una estructural relacional y dinámica».

90 La mayoría de las opiniones en este sentido se han vertido en el ámbito natural de las normas de conflicto: las relaciones jurídico-privadas. Teniendo en cuenta esta precisión, la vertiente conflictual del reconocimiento mutuo ha sido admitida, con particularidades y matices, $\mathrm{R}$. MICHAELS (2006): «EU Law as Private International Law? Re-Conceptualising the Country-OfOrigin Principle as Vested Rights Theory», ZERP Diskussionspapier 5, 13 y ss.; (2008b): 1628 y ss.; o S. NICOLIN (2005): 217 y ss. Entre las tesis «alternativas», destaca J. BASEDOW (1994): Conflicts of Economic Regulation, American Journal of Comparative Law 42(2), 447, quien considera al principio de país de origen como una regla de conflicto alternativa, en virtud de la cual los concursos de leyes se solucionarían aplicando la norma más favorable al prestador. Otras opiniones, como la de F. J. GARCIMARTÍN ALFÉREZ (2014: 343-344), con cita de la STJCE de 9 de marzo de 1999 (C-212/97, Centros) y del principio del país de origen, afirman que las normas de conflicto también pueden funcionar como «normas de reconocimiento», afirmando que esto implica el reconocimiento «de una relación preconfigurada bajo una ley extranjera o de un derecho adquirido bajo una ley extranjera». También en el contexto del Derecho Privado, M. LEHMANN (2016): El reconocimiento ¿Una alternativa al Derecho Internacional Privado? Cuadernos de Derecho Transnacional 8(2), 240 y ss., se cuestiona sobre la superación o complementariedad de las normas de conflicto por parte del reconocimiento mutuo, atribuyendo a este último su capacidad para lograr los mismos objetivos del Derecho Internacional Privado. El paralelismo con las normas de conflicto es también planteado por M. GUZMÁN ZAPATER (1998): El principio del reconocimiento mutuo: ¿un nuevo modelo para el Derecho Internacional Privado comunitario?, RDCE 3, 144, aunque plantea lógicas dudas al constatar diferencias entre las clásicas normas de conflicto y el reconocimiento mutuo. La autora termina asumiendo un planteamiento sugerente. Señala que, puesto que el principio del reconocimiento mutuo es un principio estructural del Derecho comunitario: "Afecta al DIPr interno pues 1) impone contrastar la idoneidad de la norma de conflicto interna y la localización que ésta realiza; 2) de modo que la ley designada sea descartada cuando impida la realización de las libertades comunitarias conforme a los parámetros del ordenamiento del país de origen»; termina afirmando que es posible que estemos ante «un incipiente sistema de DIPr basado en la idea de reconocimiento» (p. 151).

Para el contexto internacional general, véase K. NICOLAIDIS y G. SHAFFER (2005): «Transnational mutual recognition regimes: Governance without global government», Law and Contemporary Problems 68; concretamente sobre la OMC, véase J. P. TRACHTMAN (2006): «Embedding Mutual Recognition at the WTO», Journal of European Public Policy Agosto. 
de las diferencias más notables se encuentra en la elección de la norma aplicable. Bajo la aplicación de las variantes del reconocimiento mutuo, la «norma de conflicto» identifica como criterio de conexión al país de origen.

A diferencia del Derecho Internacional Privado, la solución del conflicto no se concreta en la aplicación de la norma de origen a un caso concreto, sino en admitir la aplicación de esa norma según fue realizada por la Administración de origen (bome country control); la consecuencia es el reconocimiento de eficacia del acto dictado en origen con base en normas que son equivalentes a las del Estado de acogida o destino. Es decir, la Administración de acogida o de destino no aplica formalmente la norma de origen, pero sí que reconoce el resultado de esa aplicación plasmada en una decisión administrativa.

Este resultado permite afirmar que el reconocimiento mutuo implica dos efectos jurídicos que son en esencia conflictuales: $\left.1 .^{\circ}\right)$ Admitir y reconocer la aplicación de la norma del país de origen conlleva asumir la consecuencia jurídica (actos administrativos con eficacia transnacional), lo que es característico de la aplicación en sentido propio de las normas; y $\left.2 .^{\circ}\right)$ Admitir y reconocer la aplicación de la norma del país de origen, lo que supone no aplicar íntegramente la norma propia.

El método conflictual presenta otras manifestaciones más complejas en las relaciones entre normas en la esfera internacional. En primer lugar, son cada vez más frecuentes conflictos entre normas de Derecho Internacional Público que comparten total o parcialmente una materia como objeto de regulación. Un tanto intuitivamente podría decirse que esas eventuales colisiones pueden quedar resueltas por la propia norma internacional ${ }^{91}$. Ahora bien, esto no siempre es así.

El problema surge cuando esas normas abordan la misma materia con orientaciones sustantivas diferentes y contradictorias. Esas colisiones pueden surgir o acrecentarse, cuando esas normas no tienen como partes al mismo número de Estados ${ }^{92}$. Dicho de otro modo, se trata de supuestos en los que dos normas internacionales no

91 Por ejemplo, véase la remisión que efectúa el art. 6 del TUE al CEDH con objeto de afrontar esas potenciales colisiones.

92 Un ejemplo en materia de derechos de autor. El Convenio de Berna de 1886 estableció la protección internacional de los derechos de autor en el marco del principio de territorialidad. Sus propias limitaciones para salvaguardar los derechos de autor de las amenazas de las nuevas tecnologías han llevado a los Estados a crear la Organización Mundial de la Propiedad Intelectual (WIPO, en sus siglas en inglés). La WIPO ha administrado la mayoría de los acuerdos multinacionales sobre propiedad intelectual por medio del Agreement on Trade Related Aspects of International Property Rights (TRIPS), concluido durante la Ronda Uruguay del GATT en abril de 1994, con la cooperación entre la OMC y la WIPO, pero también mediante el European Convention Relating to Questions on Copyright Law and Neighboring Rights in the Framework of Transfrontier Broadcasting by Satellite, del mismo modo que con base en los «WIPO Internet Treaties» y de las medidas normativas adoptadas por la Unión Europea (Reglamento 40/94, de 20 de diciembre, modificado sucesivamente; Directiva 93/83/CEE del Consejo, de 27 de septiembre, sobre Coordinación de determinadas disposiciones relativas a los derechos de autor y derechos afines a los derechos de autor en el ámbito de la radiodifusión vía satélite y de la distribución por cable; Directiva 91/250/CEE del Consejo, de 14 de mayo, sobre la protección jurídica de programas de ordenador). 
pueden ser objeto de aplicación conjunta, o bien de una aplicación alternativa coherente con base en los aforismos clásicos lex posterior derogat anterior o lex specialis derogat generalis conforme al art. 30.III de la Convención de Viena sobre el Derecho de los Tratados ${ }^{93}$. La doctrina aborda estas colisiones entre normas reivindicando el método conflictual $^{94}$.

El último ámbito en el que se propugnan soluciones conflictuales es más indeterminado y difuso. En este ámbito, los conflictos aplicativos que puedan surgir tienen lugar entre «normas» (privadas) internacionales y normas de ordenamientos estatales e internacionales convencionales, no se pueden solucionar con base en las reglas clásicas que regulan las relaciones entre normas o entre ordenamientos. Aquí entran en colisión «normas» con diferentes grados de obligatoriedad y precisión, pero con plena vocación supraterritorial. En este marco, los problemas jurídicos no sólo tienen que ver tanto con la eventual aplicación y asunción por Estados y organizacio-

En conclusión, la aplicación del Derecho Internacional en esta materia se debate entre las relaciones estrictamente bilaterales, condicionadas por otras muchas normas de Derecho Internacional, en la medida en que los Estados sean Parte en todas o parte de ellas, y sin perjuicio, finalmente, de la aplicación del Derecho Europeo, en función de la pertenencia a la Unión Europea.

93 Uno de los supuestos más estudiados tiene lugar en la confluencia de las numerosas normas de protección ambiental y el Derecho comercial internacional de la OMC. M. HILF (2000): « ¿Libertad del comercio mundial contra protección del medio ambiente?», Rv. Electrónica de Estudios Internacionales 1, analiza esos conflictos mostrando cómo ni la regla de lex posterior, ni la de lex specialis permiten solucionarlos. La primera, porque, aunque en un principio la gran mayoría de los acuerdos internacionales sobre la protección del medio ambiente podían reclamar su primacía frente al GATT 1947, tras la creación de la OMC en 1994, éstos habrían quedado en desventaja, a menos que les fuera otorgada de nuevo la preferencia mediante un protocolo suplementario. Respecto a la segunda, porque la regla lex specialis podría ser aplicada en favor de ambos cuerpos normativos.

Un ejemplo de este tipo de colisión podría ser el conflicto entre el Agreement on Trade Related Aspects of International Property Rights (el TRIPS aprobado por la WIPO, en cooperación con la OMC) y la Convention on Biological Diversity (Cartagena Protocol on Biosafety to the Convention on Biological Diversity, en el marco de la UNEP), en lo referente a los derechos de propiedad intelectual sobre material genético. Ambas normas inciden esa materia de forma contradictoria; la primera intentando otorgar un régimen unitario a todos los derechos de propiedad intelectual; la segunda, incorporando en sus arts. 16.5 y 22 previsiones formuladas para contemporizar la influencia del TRIPS y, particularmente, sus efectos sobre: a) El reconocimiento de las patentes y otros derechos de propiedad intelectual que utilizan recursos genéticos; y b) El conocimiento tradicional sin prior informed consent en lo concerniente al access and benefit sharing, justo donde el art. 27.3.b) del TRIPS sí exige autorización.

94 Téngase en cuenta las implicaciones de Derecho Privado en muchos de esos conflictos. En relación con los derechos de autor, G. B. DINWOODIE (2000): «A new copyright order. Why national Courts should create global norms», University of Pennsylvania Law Rw 149 , y A. FISCHER-LESCANO y G. TEUBNER (2004). Estos últimos también ponen el ejemplo del Derecho de patentes (conflicto Brasil-EE.UU./OMS-OMC por la autorización de la producción de genéricos contra el SIDA). Este método ha sido reivindicado para el Derecho Público por C. U. SCHMID (1999): «Diagonal Competence Conflicts between European Competition Law and National Regulation», European Rw of Private Law 8(1), M. EVERSON y C. JOERGES (2006), C. JOERGES (2010) o K-H. LADEUR (2010).

N.o 103, septiembre-diciembre 2018, págs 155-190 
nes internacionales de dichas normas ${ }^{95}$, como con los conflictos que pueden surgir con ese tipo de normas ${ }^{96}$.

Parece obvio decir que en este ámbito tampoco existe una ausencia de reglas estructurantes de las relaciones entre órdenes normativos ${ }^{97}$. ¿Cómo cabe abordar, entonces, los conflictos aplicativos que puedan surgir entre este tipo de normas y los ordenamientos estatales e internacionales? De nuevo, aquí también se recurre de un modo amplio e impropio a hablar de conflictos o colisiones de normas.

En los dos últimos grupos de casos expuestos, el recurso a los conflictos de normas debe entenderse como un intento sugerente de reconceptualización. Quienes abogan por esta perspectiva, son conscientes de la originalidad con que se plantea la conflictualidad. Primero, porque esta perspectiva conflictual no es uniforme y está bastante alejada de la concepción clásica. Segundo, porque se plantea la apertura del sistema conflictual hacia «normas de conflicto» dinámicas y ponderadas que atiendan a nuevos criterios de determinación de la norma aplicable y que puedan dar soluciones ajustadas a cada caso.

\section{De la concepción autoritaria y centrada en situaciones jurídicas estáticas, a una concepción ex parte civium y focalizada en relaciones jurídicas dinámicas}

Todo el complejo conjunto normativo que hemos analizado en el apartado anterior no deja de ser, en principio, Derecho Administrativo. Su objeto primordial sigue siendo la actividad de las Administraciones (a cualquier nivel territorial) y sus relaciones con los ciudadanos, o de estos entre sí, cuando esas relaciones presentan rele-

95 En el sector agroalimentario se ha verificado un aumento de las exigencias concernientes tanto a la inocuidad del producto, como al compromiso con valores éticos empresariales relacionados a la protección ambiental y a los derechos laborales, entre otros. Los Estados suelen optar por normalizar la materia en cuestión con una norma técnica pública tras verificar la tendencia generalizada del sector privado de exigir un determinado certificado de calidad. Éste es el caso de los certificados de productos orgánicos, los cuales, tras ganar fuerza en el sector privado, fueron regulados por la Comunidad Europea con los Reglamentos n. ${ }^{\circ}$ 2092/91 y 1788/2001 relativos, respectivamente, a los requisitos de la producción orgánica y a las reglas de inspección de los productos orgánicos provenientes de países en desarrollo.

96 Los Estados Parte de la Organización Mundial de Sanidad Animal han expresado su preocupación por la importancia creciente de las normas privadas en los intercambios de productos de origen animal y por el posible conflicto entre las normas oficiales y las normas elaboradas por organizaciones privadas normativas. En torno a estas cuestiones, uno de los conflictos más conocidos es el que surge entre las normas privadas de la GlobalGAP (antes EurepGAP), la más extendida en el mundo (se trata de una entidad privada dedicada a aprobar normas voluntarias de «buenas prácticas agrícolas» y para la certificación de productos agrícolas), y otras normas públicas oficiales tanto en el contexto OMC, como en relación con la Organización Mundial de Sanidad Animal (OIE), la Comisión del Codex Alimentarius (CCA) y la Convención Internacional de Protección Fitosanitaria (CIPF).

97 Especialmente sugestiva es la afirmación de N. WALKER (2008): «Beyond boundary disputes and basic grids: Mapping the global disorder of normative orders», ICON 6(3 y 4), 385 y ss., al referirse al «new disorder of orders». El autor señala que el principio de territorialidad soberano compite con otros principios que le disputan la prevalencia como meta-principio ordenante de las relaciones entre órdenes jurídicos (bierarchical, unipolar, regional, integrity-based, legal-field, y pluralist approaches). 
vancia jurídico-pública. Sin embargo, hay un cambio relevante: el Derecho Administrativo transnacional potencia una orientación dinámica y «desde abajo».

La primera razón que motiva este enfoque es el reconocimiento de efectos supraterritoriales al ejercicio de derechos por virtud del reconocimiento mutuo entre Estados (típicamente, derechos de tipo económico como las libertades comunitarias). La homogeneización y equiparación de los ordenamientos nacionales en el seno de la Unión Europea, u otras organizaciones internacionales, ha servido para establecer las condiciones mínimas en las que el ejercicio de esos derechos puede tener una eficacia transnacional.

Esta premisa se concreta, en segundo lugar, en la relevancia que adquieren las posiciones jurídicas de los titulares de esos derechos en las relaciones jurídicas que entablan. Esta afirmación implica la superación del carácter estático y centrado en situaciones jurídicas más propio de la concepción autoritaria del Derecho Administrativo $^{98}$. La transnacionalidad potencia, por el contrario, las situaciones jurídicas activas para proyectarlas en diferentes estadios de la relación jurídica. Esa proyección se hace depender, además, de la relevancia jurídica que se otorga a la autonomía de la voluntad del titular de derechos para elegir el Derecho aplicable en contextos de «competencia entre ordenamientos» ${ }^{99}$. En definitiva, lo fundamental no es la situación jurídica estática que habilita actuar, sino el hecho de que la posición jurídica del titular de derechos puede cambiar en función de las decisiones que adopte. Por esta razón, esa posición no es siempre activa o pasiva, sino mutable en función del estado de la relación. Piénsese, de nuevo, en la operatividad del reconocimiento mutuo y se comprenderá que esta afirmación es una consecuencia tanto del sometimiento de las fases de la relación a diferentes ordenamientos jurídicos, como de su aplicación por distintas Administraciones.

El equilibrio de las partes de la relación jurídica viene sustentado, en tercer lugar, por otra serie de fenómenos que ponen de manifiesto la posición central que adquieren los derechos e intereses de los particulares ${ }^{100}$. A ello ya contribuyó de forma determi-

98 Tradicionalmente, la ciencia jurídico-administrativa ha prestado una especial atención a las potestades públicas y, como contrapartida, a los deberes jurídicos de los administrados. El reconocimiento de auténticas relaciones jurídicas entre el Estado y los ciudadanos contaba con la reticencia de la propia Administración. De hecho, cuando se instauraban relaciones jurídico-administrativas se hacía estableciendo una relación de prevalencia en muchos casos insalvable. El mejor ejemplo es la relación tributaria. Véase J. E. SORIANO GARCÍA (1979): «Evolución del concepto “relación jurídica” en su aplicación al Derecho Público», Rv. de Administración Pública 90.

99 M. GNES (2004): La Scelta del Diritto. Concorrenza tra ordinamenti, arbitraggi, diritto comune Europeo, Milán: Giuffrè, 459; F. VIOLA (2007): «Il diritto come scelta», A. PLAIA, La competizione tra ordinamenti giuridici, Milán: Giuffrè, 197-198; R. MICHAELS (2008a: 130-133) y J. AGUDO GONZÁLEZ (2015: 372 y ss.).

${ }_{100}$ No se puede desconocer que desde sus orígenes el Derecho Administrativo ha incorporado una orientación hacia el equilibrio entre el poder público y los derechos y garantías de los ciudadanos. En esta dirección, E. GARCÍA DE ENTERRÍA e I. BORRAJO INIESTA (2013: 193) y A. Von BOGDANDY (2013: 318 y ss.). Ahora bien, tampoco se puede negar que la concepción autoritaria del Derecho Administrativo ha sido la versión explicativa más exitosa. Las razones ya han sido expuestas y están vinculadas a los procesos de transformación política y jurídica en el siglo XIX. 
nante la constitucionalización del Derecho Administrativo ${ }^{101}$, pero los nuevos fenómenos que mencionamos a continuación descubren un nuevo marco para fortalecer un Derecho Administrativo ex parte civium. Se advierte de que ninguno de estos fenómenos es un compartimento estanco, siendo evidentes las interacciones y los solapamientos:

a) La globalización de la economía tiene un efecto determinante en la influencia de actores mixtos o estrictamente privados sobre la creación y la aplicación del Derecho. Como hemos insistido, se multiplican las organizaciones/agrupaciones/asociaciones cuya finalidad es la regulación de intereses privados y cuyas normas son incluso asumidas por los propios Estados, ante la imposibilidad de que estos regulen la economía en su contexto internacional. Se produce, en definitiva, una anticipación de la definición de los intereses privados sobre la determinación de los intereses públicos, para cuya determinación la Administración nacional pierde, por tanto, el monopolio.

b) La liberalización y la «cesión» al mercado de actividades y servicios trandicionalmente asumidas por las Administraciones a operadores privados, no implica una dejación de la regulación por parte del Derecho Administrativo. Muy al contrario, estos ejemplos demuestran que el Derecho Administrativo aborda con normalidad la ordenación de relaciones jurídicas que son auténticas relaciones de Derecho Privado (relaciones entre usuarios y consumidores y prestadores de servicios económicos de interés general, por ejemplo). Ahora bien, es innegable que la liberalización conlleva un menor intervencionismo público y, por ello, la «devolución» al régimen jurídico-privado de las actividades liberalizadas (sin perjuicio de las funciones de supervisión y garantía del Estado). En última instancia, esto significa una mayor libertad de los operadores económicos frente a los Estados ${ }^{102}$.

c) La tendencia hacia la aplicación de principios y métodos de Derecho Privado a entidades y Administraciones públicas. Cabe destacar la utilización de instrumentos típicamente iusprivatistas por parte de las autoridades públicas (contractualización ${ }^{103}$ ). Esta tendencia también tiene una explicación en términos legitimatorios: la búsqueda de la negociación y de la autonomía de la voluntad, descubre la procura de formas de legitimación que compensen la pérdida de legitimación democrática ${ }^{104}$.

El afianzamiento de los intereses y derechos privados que puede deducirse de estos fenómenos, ha sido, sin embargo, objeto de críticas al considerar que sus máximos

101 Por todos, R. WAHL (2013): Los últimos cincuenta años del Derecho Administrativo alemán, MadridBarcelona: Marcial Pons, 33 y ss.

102 En esta dirección, C. HARLOW (1998), citando a V. SCHMIDT.

103 Véase, E. SCHMIDT-ASSMANN (2017): «La contractualización del Derecho Administrativo», A. MONTAÑA PLATA y J. I. RINCÓN CÓRDOBA, Contratos Públicos: Problemas, perspectivas y prospectivas, Bogotá: Universidad Externado.

104 En este sentido, L. CASINI (2013: 37). 
beneficiarios son las grandes corporaciones multinacionales. Esta afirmación es cierta, pero no puede servir para ocultar los millones de ciudadanos y pequeñas empresas que se ven beneficiados por la libre circulación y el reconocimiento mutuo.

\section{Title}

The overcoming of territorial paradigm and its effects in Administrative Law. Normative Basis of Transnational Administrative Law

\section{Summary}

I. Introduction. II. The Territoriality Principle in the State General Theory and in the Legal Theory. 1. The territoriality and exclusivity principles of sovereign power. 2. State law «toward outward». 2.1. Foundations of international law. 2.2. Conflicts of laws and private international Law. III. The Loss of Centrality of the Territoriality Principle. 1. The overcoming of the exclusivity of State law. 1.1. Legal fragmentation and international (private) «norms». 1.2. Administrative law is international law and vice versa. 1.3. Relations between State legal orders. 2. The overcoming of the division public law versus private law. IV. Final Remarks: the «Relational Character» of the Transnational Administrative Law. 1. From the exclusivity and the completness of the State Administrative Law to the relations between legal orders and conflicts of law. 2. From an authoritarian conception centered in static legal status, to a conception ex parte civium and focused on dynamic legal relationships.

\section{Resumen:}

El Derecho Administrativo aborda con creciente frecuencia fenómenos jurídicos que podemos denominar como «transnacionales». Esta calificación se debe a que no son susceptibles de una ordenación integral por el Derecho Administrativo estatal. En este estudio abordamos el análisis de esos fenómenos jurídicos desde la perspectiva del principio de territorialidad. El objetivo es mostrar los efectos de la incompatibilidad de fenómenos inherentes a la globalización con el paradigma de la territorialidad del Derecho Administrativo y su concepción estatutaria como Derecho del Estado. El estudio comienza con una exposición sobre la trascendencia del principio de territorialidad en la Teoría General del Estado y en la Teoría jurídica; esta parte analiza la relevancia del territorio como base y límite del poder público, y en las relaciones con otros ordenamientos. A continuación, el estudio aborda los fenómenos jurídicos alumbrados en el 
contexto actual de fragmentación y pluralismo jurídico, para mostrar una realidad jurídica que condiciona la capacidad explicativa del principio de territorialidad. La constatación de la superación del paradigma territorial del Derecho Administrativo provoca la necesidad de afrontar las consecuencias de ese panorama jurídico transformador. El estudio muestra cómo la desterritorialización del Derecho tiene implicaciones directas no sólo en las relaciones entre órdenes normativos, sino también en la summa divisio, al igual que en la vis autoritaria que tradicionalmente ha caracterizado al Derecho Administrativo. Estas transformaciones abren paso a un Derecho Administrativo no exclusivamente estatal, basado en relaciones interordinamentales y focalizado en relaciones jurídicas dinámicas.

\begin{abstract}
:
Administrative Law is increasingly tackling with legal phenomena that can be named as «transnational». This denomination is due to the fact that cannot be embraced entirely by State Administrative Law. In this paper we approach the analysis of these legal phenomena from the perspective of the territoriality principle. The objective of this paper is to show the effects of the incompatibility of a legal phenomenon inherent to globalization, with the paradigm of the territoriality of Administrative Law and its statutory conception as State law. The study begins with an exposition on the relevance of the territoriality principle in the State General Theory and in the Legal Theory; for this reason, we analyze the relevance of the territory as the basis and limit of public power, but also in the relations other legal orders. Then the study deals with the current context of fragmentation and legal pluralism to show a legal reality that undermines the explanatory capacity of the territoriality principle. The verification of the overcoming of the territorial paradigm of Administrative Law causes the need to face the consequences of this transforming legal reality. The paper shows to what extent the deterritorialization of law has direct implications not only in the relations between legal orders, but also in the «summa divisio» and in the traditional authoritarian characterization of Administrative Law. These changes open the scene to a non-statist legal regime, based on relations between legal orders and focused on dynamic legal relations.
\end{abstract}

\title{
Palabras clave:
}

Principio de territorialidad, relaciones interordinamentales, conflictos de normas, relaciones jurídico-administrativas, Derecho Administrativo transnacional.

\section{Key words:}

Territoriality principle, relations between legal orders, conflicts of law, administrative legal relationships, transnational administrative law. 